\title{
Efeito do Curativo de Demora com EGCG, Derivada do Chá Verde, na Lesão Periapical em Cães
}

\author{
Dissertação apresentada à Faculdade de \\ Odontologia de Ribeirão Preto da Universidade \\ de São Paulo, para obtenção do título de Mestre \\ em Ciências. \\ Programa: Odontopediatria \\ Área de Concentração: Odontopediatria \\ Orientador: Profa. Dra ${ }^{\mathrm{a}}$. Andiara De Rossi
}

Ribeirão Preto 
AUTORIZO A REPRODUÇÃO E DIVULGAÇ̃̃O TOTAL OU PARCIAL DESTE TRABALHO, POR QUALQUER MEIO CONVENCIONAL OU ELETRÔNICO, PARA FINS DE ESTUDO E PESQUISA, DESDE QUE CITADA A FONTE.

FICHA CATALOGRÁFICA

\section{Liévana, Fernanda Souza}

Efeito do curativo de demora com EGCG, derivada do chá verde, na lesão periapical em cães. Ribeirão Preto, 2018.

91p.: il.; $30 \mathrm{~cm}$

Dissertação de Mestrado apresentada à Faculdade de Odontologia de Ribeirão Preto da Universidade de São Paulo. Área de concentração: Odontopediatria.

Orientador: De Rossi, Andiara

1. Epigalocatequina-3-galato 2. Medicação intracanal 3. Periodontite apical. 


\section{FOLHA DE APROVAÇÃo}

Liévana, Fernanda Souza. Efeito do curativo de demora com EGCG, derivada do chá verde, na lesão periapical em cães.

Dissertação apresentada à Faculdade de Odontologia de Ribeirão Preto da Universidade de São Paulo, para a obtenção do Título de Mestre em Ciências.

Área de Concentração: Odontopediatria

Aprovado em:

BANCA EXAMINADORA

Prof.Dr.

Instituição:

Julgamento: Assinatura:

Prof.Dr.

Instituição:

Julgamento: Assinatura:

Prof.Dr.

Instituição:

Julgamento: Assinatura: 



\section{Fernanda SOUZa LIÉVANA}

Nascimento 15 de janeiro de 1993, São José do Rio Preto, Brasil

Filiação Luiz Fernando Góes Liévana

Regina Fátima Souza Liévana (in memorian)

2012-2016 Graduação em Odontologia

Faculdade de Odontologia de Ribeirão Preto

Ribeirão Preto, Brasil

2017-2018 Mestrado em Ciências

Área de Concentração: Odontopediatria

Faculdade de Odontologia de Ribeirão Preto da Universidade de São Paulo - FORP/USP, SP, Brasil 



\section{Dedicatória}

À Deus, que me deu a vida e a oportunidade de estar exatamente onde estou.

Ao meu avô, Emílio, um anjo que me guia por toda a vida.

À minha mãe, que me ensinou a ser forte e hoje me ampara do céu. 



\section{Agradecimentos Especiais}

Ao meu pai, Luiz Fernando Góes Liévana. Você me deu a vida e depois me ensinou a sonhar. Obrigada por confiar em mim e sempre se esforçar para eu realizar meus sonhos. Sem você me orientando e me apoiando do outro lado, eu não teria conseguido chegar aonde cheguei. Amo você.

Ao meu irmão, Danilo Pedro Souza Carrilho. Obrigada por ser sempre presente mesmo quando a distância pudesse atrapalhar. Você é minha maior ligação com a mamãe.

Às minhas avós, Dayse e Sebastiana. Obrigada por serem mais que avós. É um privilégio conviver com vocês duas.

À toda minha familia, agradeço por todo o amor que sempre me deram, vocês são parte disso também.

À Fabiola Perri Venturini Ponciano, obrigada pela convivência, por ser mais do que uma terapeuta para mim, por não me deixar desistir dos meus sonhos, por me fazer enxergar o mundo com olhos mais leves e por acalmar meu coração quando eu achei que não fosse possível. Essa conquista é sua também. Obrigada!

Aos meus amigos votuporanguenses, agradeço pelo suporte durante toda minha vida! Obrigada por serem um porto seguro para mim e por sempre torcerem pelo meu sucesso, mesmo que de longe. Amo vocês.

A minha turma de faculdade, minha família em Ribeirão Preto, obrigada pelo apoio, pelas experiências compartilhadas e pela saudade que só me mostra como fomos 
felizes juntos. Vocês são mais que amigos, são irmãos que a vida me deu. Não poderia ter chegado até aqui sem vocês ao meu lado, muito obrigada!

À minha amiga e vizinha Giovana Gonçalves Martins, você foi essencial para que eu conseguisse alcançar meus objetivos. Obrigada pelos sonhos compartilhados, pelas conversas motivadoras, pelos momentos felizes e também pelos tristes, estes que ficaram mais fáceis com sua presença. Espero que nossa caminhada esteja apenas começando! Te amo, amiga. 


\section{Agradecimentos Especiais}

À minha orientadora Profa. Dra. Andiara De Rossi, por ter me acolhido desde a graduação e sempre segurar minha mão quando eu hesitei cair. Obrigada por todos os ensinamentos, tanto na vida acadêmica quanto na pessoal, eu aprendo muito com você. Obrigada por ter tido paciência quando eu não sabia o que fazer, quando eu tentei fraquejar e quando eu não correspondia com suas expectativas. Eu não me imagino ao lado de outra pessoa nessa caminhada. Que Deus continue te iluminando para fazer o que fez por mim aos jovens que almejam a vida acadêmica. Muito obrigada!

"Ninguém cruza nosso caminho por acaso, e nós não entramos na vida de alguém sem nenhuma razão."

Chico Xavier 



\section{Agradecimentos}

À Faculdade de Odontologia de Ribeirão Preto da Universidade de São Paulo, na pessoa da atual Diretora Profa. Dra. Léa Assed Bezerra da Silva e do Vice-diretor Prof. Dr. Arthur Belém Novaes Júnior.

À Coordenação do Curso de Pós-Graduação em Odontopediatria da Faculdade de Odontologia de Ribeirão Preto da Universidade de São Paulo, na pessoa da coordenadora, Profa. Dra. Raquel Assed Bezerra Segato. Obrigada por sempre estar disposta a nos ajudar e ensinar, é uma honra fazer parte deste Programa.

Aos professores da disciplina de Odontopediatria do departamento de Clínica Infantil da Faculdade de Odontologia de Ribeirão Preto da Universidade de São Paulo: Prof. Dr. Paulo Nelson-Filho, Profa. Dra. Raquel Assed Bezerra Segato, Profa. Dra. Maria Cristina Borsatto, Prof ${ }^{a}$. Dra. Alexandra Mussolino de Queiroz, Profa. Dra. Aldevina Campos de Freitas, Prof ${ }^{a}$. Dra . Kranya Victoria Diaz Serrano, Prof. Dr. Fabrício Kitazono de Carvalho pelo aprendizado diário, pelas experiências compartilhadas e por todos os ensinamentos transmitidos.

Ao Prof. Dr. Francisco Wanderley Garcia de Paula e Silva e à Cirurgiã-dentista do departamento Dra Carolina Paes Torres Mantovani por todo companheirismo durante esses dois anos. Obrigada pela ajuda nas clínicas e por todo conhecimento que me foi dado.

Aos professores da disciplina de Ortodontia do departamento de Clínica Infantil da Faculdade de Odontologia de Ribeirão Preto da Universidade de São Paulo: Prof. Dr. Fábio Lourenço Romano, Profa. Dra. Mirian Aiko Nakane Matsumoto, Prof. Dr. José Tarcísio Lima Ferreira, Prof. Dr. Murilo Fernando Neuppman Feres, Profa. Dra Maria Bernadete Sasso Stuani obrigada pela convivência, pelos ensinamentos e por sempre deixarem as portas abertas para mim. 
Aos pós-graduandos do Programa de Odontopediatria da Faculdade de Odontologia de Ribeirão Preto da Universidade de São Paulo, obrigada pela convivência, trocas de experiências, pelos sorrisos de todos os dias e por tanta ajuda nesses dois anos.

À Profa. Dra. Danielly Cunha Araújo Ferreira, obrigada pelo desenvolvimento deste projeto o qual eu tive o prazer em dar continuidade.

À todo o pessoal técnico envolvido no desenvolvimento deste trabalho, Marco Antonio dos Santos, Nilza Letícia Magalhães e Marilia Pacífico Lucisano. Obrigada!

A todos os funcionários da Faculdade de Odontologia de Ribeirão Preto da Universidade de São Paulo, especialmente aos funcionários do Departamento de Clínica Infantil: Filomena Leli Placciti, Matheus Morelli Zanela, Micheli Cristina Leite Rovanholo e Rosemary Alves de Sá, pela atenção, pela convivência, pelo empenho em ajudar e por sempre estarem sorrindo.

"Quem caminha sozinho pode até chegar mais rápido, mas aquele que vai acompanhado, com certeza vai mais longe."

Clarice Lispector 


\section{RESUMO}

Liévana, FS. Efeito do curativo de demora com EGCG, derivada do chá verde, na lesão periapical em cães. Ribeirão Preto, 2018. 91p. Dissertação [mestrado]. Faculdade de Odontologia de Ribeirão Preto, Universidade de São Paulo.

O chá verde vem sendo utilizado na prevenção e tratamento de variadas doenças infecciosas e imunoinflamatórias, por apresentar efeitos benéficos decorrentes da presença de Epigalocatequina-3-galato (EGCG). Esta catequina apresenta papel antiinflamatório, anti-oxidante, anti-microbiano e mineralizador e poderia ser utilizado no tratamento da doença periapical. O objetivo do presente trabalho foi avaliar o efeito uma pasta à base de EGCG utilizada como curativo de demora em lesões periapicais experimentalmente induzidas em cães. Um total de 80 raízes de pré-molares de cão com rizogênese completa e lesões periapicais experimentalmente induzidas, foram aleatoriamente divididos em 4 grupos submetidos à diferentes protocolos de tratamento endodôntico: 1) curativo de demora com pasta à base de EGCG; 2) curativo de demora com EGCG em veículo aquoso; 3) curativo de demora com pasta à base hidróxido de cálcio (Pasta Calen); 4) tratamento endodôntico em sessão única. Para avaliação da resposta tecidual, os dentes foram avaliados radiograficamente e histopatologicamente. As imagens radiográficas obtidas antes e 120 dias após o tratamento, foram fotografadas e digitalizadas para o programa Image J 1.28 para mensuração das áreas $\left(\mathrm{mm}^{2}\right)$ radiolúcidas periapicais. Aos 120 dias após a obturação doa canais radiculares os animais foram eutanasiados e os espécimes foram processados histotecnicamente, corados com HE e avaliados com microscopia de luz convencional e de fluorescência (infiltrado inflamatório, espessamento do ligamento periodontal e reabsorção de tecidos mineralizados). Os resultados obtidos foram analisados estatisticamente utilizando os testes quiquadrado, Fisher, Anova e pós teste de Tukey, com nível de significância de 5\% em todos os testes. De acordo com os resultados radiográficos, o percentual médio de redução da área radiolúcida ( \pm erro padrão da média) foi semelhante $(p>0,05)$ nos grupos EGCG em veículo aquoso (64,57\%; $\pm 7,514)$; pasta à base de EGCG (59,95\%; $\pm 8,023)$ e pasta à base de hidróxido de cálcio $(58,65 \% ; \pm 6,192)$. Todos foram superiores ao grupo tratado em sessão única $(19,49 \% ; \pm 2,881)(p<0,01)$. A análise 
histopatológica mostrou que os grupos que receberam aplicação de curativo de demora com EGCG ou hidróxido de cálcio, apresentaram reaparação da lesão periapical com semelhança em todos os parâmetros avaliados. Por outro lado, o tratamento em sessão única resultou em manutenção da lesão periapical, com maior espessura do ligamento periodontal $(p<0,001)$, persistência de infiltrado inflamatório moderado ou severo $(p<0,01)$ e presença de reabsorção óssea e cementária $(p<0,0001)$. Foi possível concluir que a pasta à base de EGCG proporcionou o reparo de lesões periapicais, constituindo possível medicação intracanal alternativa.

Palavras-chave: Epigalocatequina-3-galato, Medicação intracanal, periodontite apical. 


\section{ABSTRACT}

Liévana, FS. Effect of intracanal dressing with EGCG, derived from green tea, in periapical lesions in dogs. Ribeirão Preto, 2018. 91p. Dissertação [mestrado]. Faculdade de Odontologia de Ribeirão Preto, Universidade de São Paulo.

Green tea has been used in the prevention and treatment of various infectious and immunoinflammatory diseases, since it has beneficial effects due to the presence of Epigallocatechin-3-gallate (EGCG). This catequin present anti-inflammatory, antimicrobial, antioxidant and mineralizing role that could be usefull in the treatment of periapical disease. The aim of the present study was to evaluate the effect of the intracanal dressing with an EGCG paste-based im periapical lesions experimentaly induced in dogs. A total of 80 dog premolar roots with complete rhizogenesis and experimentally induced periapical lesions were randomly divided into 4 groups submitted to different endodontic treatment protocols:1) intracanal dressing with EGCG based paste; 2) intracanal dressing with EGCG in aqueous vehicle; 3) intracanal dressing with based paste on calcium hydroxide (Calen paste); 4) single session endodontic treatment. To evaluate the tissue response, the teeth were evaluated radiographically and histopathologically. Radiographic images are selected before 120 days after treatment, were photographed and scanned for the program Image J 1.28 for the measurement of periapical radiolucent areas (mm2). To 120 days after the root canal filling animals were euthanasied and the specimens processed, stained in the rotin $\mathrm{HE}$ and evaluated under conventional and fluorescence microscopy (inflammatory infiltrate, periodontal ligament space and mineralized tissue resorption). The results were compared statistically using chisquare, Fisher, Anova and Tukey post-test, with a significance level of $5 \%$ in all tests. According to the radiographic results, the mean percentage reduction of the radiolucent area (standard pattern of the mean) was similar ( $p>0.05$ ) in the EGCG groups in aqueous vehicle $(64.57 \% ; \pm 7.514)$; EGCG based paste $(59.95 \%, \pm 8.023)$ and calcium hydroxide based paste $(58.65 \%, \pm 6.192)$. All groups were higher for the group treated in single session $(19.49 \%, \pm 2.881)(p<0.01)$. The histopathological analysis showed that the groups that received the prescription of intracanal dressings with EGCG or calcium hydroxide, resulted in periapical lesion 
repair and were similar in all the evaluated parameters. However, treatment in single session did not repair the periapical lesion resulting in greatest measure of the periodontal ligament $(p<0.001)$, persistence of moderate or severe inflammatory infiltrate $(p<0.01)$ and presence of bone and cementum resorption $(p<0.0001)$. It is possible to conclude that EGCG paste-based allows the periapical lesions repair, constituting possible alternative intracanal medication.

Key Words. Epigallocatechin-3-gallate, Intracanal dressing, apical periodontitis. 


\section{SUMÁRIO}

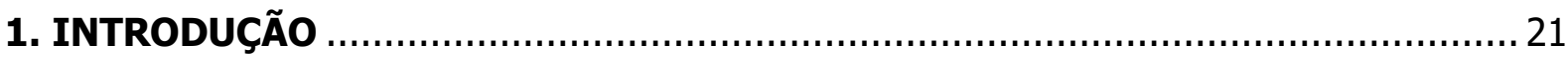

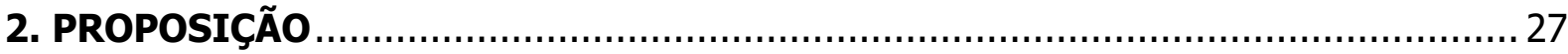

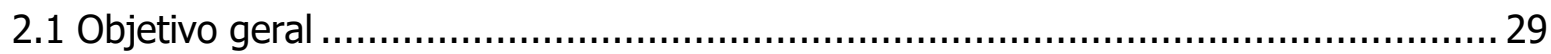

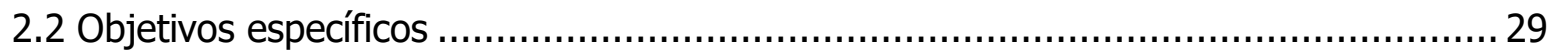

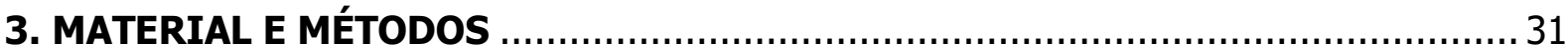

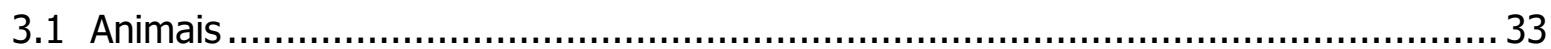

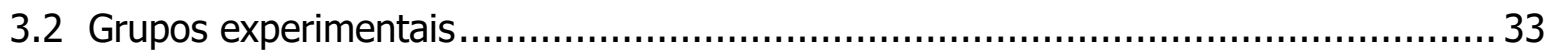

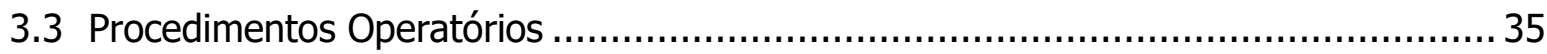

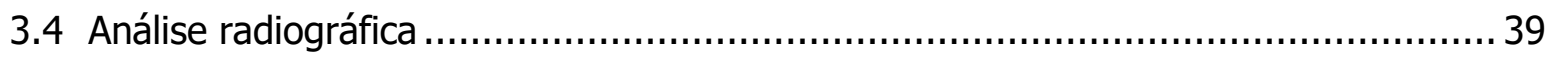

3.5 Processamento histotécnico e análise histopatológica .................................... 39

3.6 Análise estatística................................................................................. 41

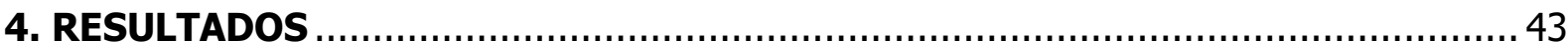

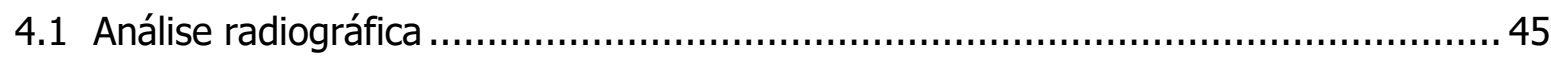

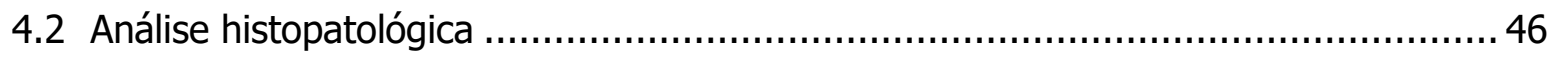

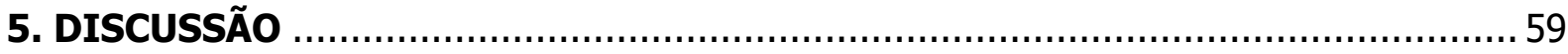

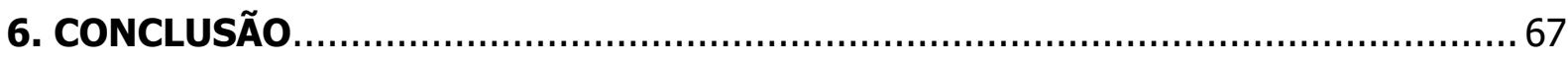

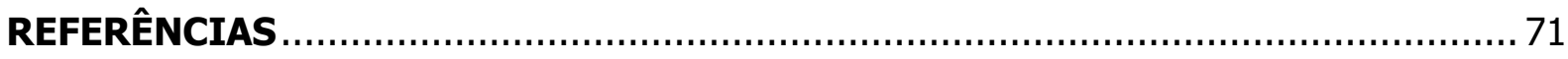

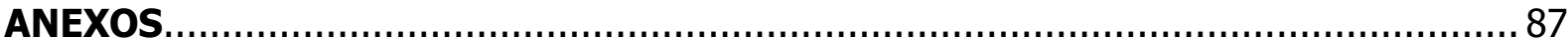



1. INTRODUÇÃo 

Um dos grandes desafios da Odontologia é o tratamento de canais radiculares em dentes portadores de necrose pulpar e lesão periapical, uma vez que o sucesso clínico, radiográfico e histopatológico nem sempre é obtido (Sjogren et al., 1997; Pirani et al., 2018). O tratamento endodôntico deve promover a redução da infecção presente no sistema de canais radiculares e região periapical, que constitui o principal agente etiológico das doenças periapicais (Kakehashi et al., 1965; Tronstad, 1992; Siqueira et al., 2011; Nobrega et al., 2016). O sucesso reduzido é decorrente de falhas no tratamento e persistência de infecção intra e extra radicular (Nair et al., 1990; Nair et al., 1999; Siqueira et al., 2011; Cardoso et al., 2016; Siqueira et al., 2016; Pereira et al., 2017), que resultam na manutenção da lesão inflamatória e reabsorção dos tecidos mineralizados, impedindo o reparo.

A infecção endodôntica é polimicrobiana com predominância de microorganismos anaeróbios Gram-negativos que possuem endotoxina ou lipopolissacarídeos (LPS) em sua parede celular e também, micro-organismos Grampositivos que tem como componente de sua parede celular o ácido lipoteicóico (LTA), moléculas extremamente tóxicas aos tecidos (Tani-Ishi, 1994; Assed, 1994; Assed et al., 1996; Leonardo et al., 2000; Hong et al., 2016; Barbosa-Ribeiro et al., 2016; Queiroz et al., 2016). Além disso, os micro-organismos não estão localizados somente na luz do canal principal, mas também no "sistema de canais radiculares" (Leonardo et al., 1994; Ribeiro, 1997; Leonardo et al., 2002; Leonardo et al., 2007; Rocha et al., 2008; Tanomaru et al., 2008; Oliveira et al., 2015; Ricucci et al., 2018). Para que ocorra o combate da infecção endodôntica, é necessário o uso de medicação tópica entre sessões com substâncias antimicrobianas, anti-inflamatórias, mineralizadoras e inativadoras de LPS e LTA eficazes, utilizadas no interior do canal radicular, denominadas curativo de demora (Bystrom et al., 1985; Byström e Sundqvist, 1985; Haasapalo e Orstavik, 1987; Dalton et al., 1998; Siqueira et al., 1999; Shuping et al., 2000; Tan e Messer, 2002; Siqueira et al., 2002; Schafer e Schlingemann, 2003; Tanomaru et al., 2008; Borsatto et al, 2016; Hidalgo et al., 2016).

A escolha da medicação intracanal deve ser criteriosa, pois visa controlar a infecção sem agredir os tecidos (Soares e Goldberg, 2001). O material de escolha deve apresentar compatibilidade tecidual, isto é, deve ter a capacidade de 
desencadear uma resposta apropriada do hospedeiro, sem produzir efeito adverso (Vert et al., 2012). Desse modo, tem-se buscado novas técnicas e materiais que sejam biocompatíveis e que promovam efetiva eliminação da microbiota envolvida na lesão periapical (Leonardo et al., 2002, De Rossi et al., 2005; Leonardo et al., 2006, Siqueira et al., 2007; Victorino et al., 2010, Silva et al., 2010).

Diversas substâncias foram propostas para serem utilizadas no canal radicular como curativo de demora entre sessões e, dentre elas, atualmente, o hidróxido de cálcio é o material mais utilizado devido às suas características biológicas satisfatórias (Silva et al., 2002; Nelson-Filho et al., 2002; Tanomaru et al., 2003; De Rossi et al., 2005; Leonardo et al., 2006; Silva et al., 2008; Silva et al., 2010; Queiroz et al., 2011; Guo et al., 2014; Adl et al., 2015; Kim e Kim, 2015; Zancan et al., 2016; Madarati et al., 2017). Visando elevar o sucesso após tratamento, outras técnicas e materiais estão sendo estudados, incluindo a associação do hidróxido de cálcio com agentes antimicrobianos mais eficazes, como a clorexidina (De Rossi et al., 2005; da Silva et al., 2008; Donyavi et al., 2016; Silva et al., 2017), a utilização de novos sistemas de irrigação por pressão negativa como o EndoVac (Cohenca et al., 2015) ou passiva como o EndoActivator (Huffaker et al., 2010; Chaudhry et al., 2017), terapia fotodinâmica antimicrobiana (Silva et. al., 2012; Archilla et al., 2012; Borsatto et al. 2016; Hidalgo et al., 2016), cimentos à base de MTA (Gomes-Filho et al., 2013; Daltoé et al., 2016; Linsuwanont et al, 2017) ou pastas poliantibióticas (Nakornchai et al. 2010; Trairatvorakul, 2012; Mehta et al. 2017). No entanto, até o momento não existe um tratamento ideal para dentes com necrose pulpar e lesão periapical, sendo necessário então aumentar os índices de sucesso clínico, radiográfico, tomográfico, microbiológico e histopatológico (Paikkatt et al., 2017).

Atualmente, os extratos à base de plantas têm sido propostos como alternativa no tratamento de variadas doenças infecciosas (Allaker e Douglas, 2009; Mehta et al., 2013; Ntie-Kang et al., 2013; Yousaf et al., 2014; Lee e Tan, 2015; Ng et al., 2017). O chá verde, planta originária da Camellia sinensis, é uma das bebidas mais populares em todo o mundo e tem se destacado dentre os agentes fitoterápicos por apresentar efeitos benéficos na saúde geral (Nagle et al., 2006; Hodgson e Croft, 2010; Suzuki e Isemura, 2013; Tarahovsky et al., 2014; Fang et al., 2015; Tenore et 
al., 2015; Pastoriza et al., 2017; Türközü e Tek, 2017). Os principais componentes químicos do chá verde são os flavonóides e as catequinas (Schmitz et al., 2005) que incluem a epigalocatequina-3-galato (EGCG), epigalocatequina (EGC), epicatequina galato (ECG) e epicatequina (EC) (Yousaf et al., 2014). No entanto, o componente mais ativo biologicamente é a EGCG (Wang et al., 2014), que constitui mais de 50\% dos polifenóis presentes (Yousaf et al., 2014; Reygaert, 2014; Chakrawarti et al., 2016).

Muitos estudos comprovam que os efeitos do chá verde na prevenção e tratamento de doenças decorrem da EGCG que apresenta ação antioxidante (Yang et al., 1998; Anghileri e Thouvenot, 2000; Wen et al., 2013; Aslan et al., 2014; Saito et al., 2014; Jayashree et al., 2017), anti-inflamatória (Yang et al., 1998; Nakanishi et al., 2010; Uchiyama et al., 2013; Wen et al., 2013; Aslan et al., 2014; Zhou et al., 2014; Fu et al., 2017; Zhao et al., 2017), antimicrobiana (Ikigai et al., 1993; Blanco et al., 2003; Taylor et al., 2005; Jeon et al., 2014; Tian et al., 2016; Lee et al., 2017), com elevado espectro de ação contra bactérias Gram-positivas e Gramnegativas (Hamilton-Miller, 2001), anti-carcinogênica (Yang et al., 1998; Suzuki e Isemura, 2013; Zhou et al., 2014; Wang et al., 2014; Yousaf et al., 2014; Butt et al., 2015; Weng et al., 2017; Moradzadeh et al., 2017), anti-hipertensiva (Basu e Lucas, 2007; Yousaf et al., 2014; Takagaki e Nanjo, 2015), biocompatível (Ferreira, 2015) e regeneradora tecidual (Sinha et al., 2014).

Na Odontologia, a EGCG vem sendo sugerida no tratamento de reabsorções de tecidos mineralizados, como doença periapical (Ferreira, 2015) e periodontal (Kudva et al., 2011; Jung et al., 2012; Narotzki et al., 2012; Asahi et al., 2014; Lagha et al., 2017), gengivite (Jenabian et al., 2012; Morin e Grenier, 2017), regeneração alveolar (Shin et al., 2014; Chang et al., 2017), erosão dental (Kato et al., 2010; Chen e Huang, 2012), halitose (Morin et al., 2015) e câncer bucal (Khurshid et al., 2016). A EGCG apresenta eficácia antimicrobiana contra grande parte de micro-organismos periodontopatogênicos, como a $P$. gengivalis (Jung et al., 2012; Asahi et al., 2014; Fournier-Larente et al., 2016) e cariogênicos como os $S$. mutans, S. sobrinus e L. casei (Vilela, 2015; Moreno, 2016). Além disso, por apresentar biocompatibilidade, a EGCG foi sugerida como meio para a conservação de dentes avulsionados após traumatismos, mantendo a vitalidade das células do 
ligamento periodontal (Hwang et al., 2011; Jung et al., 2011; Ghasempour et al., 2015).

Estudos in vitro revelaram que os polifenóis do chá verde também apresentam eficácia antimicrobiana contra grande parte das linhagens de bactérias isoladas do canal radicular (Horiba et al., 1991), incluindo o E. faecalis (Prabhakar et al., 2010), espécie comumente detectada em lesões refratárias ao tratamento endodôntico (Stuart et al., 2006) e também pode auxiliar na terapia endodôntica regenerativa (Lee et al., 2009; Pheenithicharoenkul e Panichuttra, 2016; Kwon et al., 2017). Um único estudo realizado em camundongos mostrou que o uso sistêmico de EGCG pode reduzir a severidade das lesões periapicais (Lee et al., 2009). No entanto, os benefícios da EGCG não foram sugeridos ou demonstrados in vivo após seu uso tópico como curativo de demora.

Diante do exposto, verifica-se que as propriedades anti-inflamatórias, antimicrobianas, mineralizadoras, antioxidantes e inibidora da reabsorção óssea induzida pelo LPS bacteriano, presentes na EGCG e que já desempenham ação sistêmica comprovada na prevenção e tratamento de diferentes doenças inflamatórias e infecciosas, também poderiam desempenhar importante papel no tratamento local da doença periapical. Em estudos anteriores realizados por nosso grupo de pesquisa foi desenvolvida uma pasta à base de EGCG, que apresentou propriedades fisicoquímicas adequadas, além de compatibilidade tecidual e ausência de alteração de cor dental (Ferreira, 2015). No entanto, seu efeito in vivo no tratamento de lesões periapicais ainda não foi avaliado. 
2. ProposiçÃO 



\subsection{Objetivo geral}

Avaliar o efeito uma pasta à base de EGCG utilizada como curativo de demora em lesões periapicais experimentalmente induzidas em dentes de cães.

\subsection{Objetivos específicos}

- Avaliar radiograficamente a redução da área radiolúcida periapical após uso do curativo de demora realizado com EGCG (veículo viscoso e aquoso), em comparação com uma pasta à base de hidróxido de cálcio e com o tratamento endodôntico realizado em sessão única;

- Comparar as características histopatológicas (infiltrado inflamatório, espessamento do ligamento periodontal e reabsorção dos tecidos mineralizados) da região periapical após utlização do curativo de demora com pasta à base de EGCG, EGCG em veículo aquoso, pasta à base de hidróxido de cálcio e tratamento endodôntico realizado em sessão única. 



\section{Material e Métodos}





\subsection{Animais}

Inicialmente o presente estudo foi submetido à apreciação pela Comissão de Ética no uso de Animais da Faculdade de Odontologia de Ribeirão Preto da Universidade de São Paulo (CEUA/FORP-USP), tendo sido aprovado (Processo $\mathrm{n}^{\circ}$ 11.1.1405.53.8 - Anexo A). Os cuidados com o bem-estar dos animais de experimentação seguiram as Normas e Princípios Éticos Adotados pela CEUA/FORPUSP e as Resoluções Normativas do Conselho Nacional de Controle de Experimentação Animal (CONCEA), regulamentadas pela Constituição Federal Brasileira na Lei no 11.794 de 8 de outubro 2008.

Foram incluídos na pesquisa 4 cães da raça Beagle, de ambos os gêneros, com 12 meses de idade e peso médio de $15 \mathrm{Kg}$. Durante todo o período de experimento os animais permaneceram no Biotério II da FORP-USP, sob cuidados de um veterinário e equipe especializada. A dieta dos animais incluiu ração e água à vontade. Antes do início dos experimentos, o preparo dos animais foi realizado por meio da aplicação de vermífugos (Drontal Puppy - Bayer - São Paulo - SP - Brasil), na dosagem de 1 comprimido a cada $10 \mathrm{~kg}$ de peso do animal, vitaminas (Glicopan Pet Vetnil Indústria e Comércio de Produtos Veterinários Ltda. - Louveira - Brasil), vacina anti-rábica (Rai-Vac I - Fort Dodge - Campinas - SP - Brasil) e Duramune (Fort Dodge) em 3 doses, com 3 semanas de intervalo entre cada aplicação. Caso apresentassem gengivite e/ou cálculo gengival, os animais foram submetidos à profilaxia, raspagem, alisamento e polimento dentário, seguidas da aplicação de digluconato de clorexidina a $0,12 \%$ (Periogard - Colgate - Palmolive - Indústria Ltda. - Brasil).

\subsection{Grupos experimentais}

Foi utilizada a EGCG (E41430; Sigma-Aldrich, St. Louis, MO, EUA), derivada do chá verde, disponível em partículas de $5 \mu \mathrm{m}$, apresentadas no estado sólido. Sua estrutura química (C22H18O11) está ilustrada na Figura 1. 
Figura 1. Estrutura química da EGCG (C22H18O11), massa molecular $458,37 \mathrm{~g} / \mathrm{mol}$.

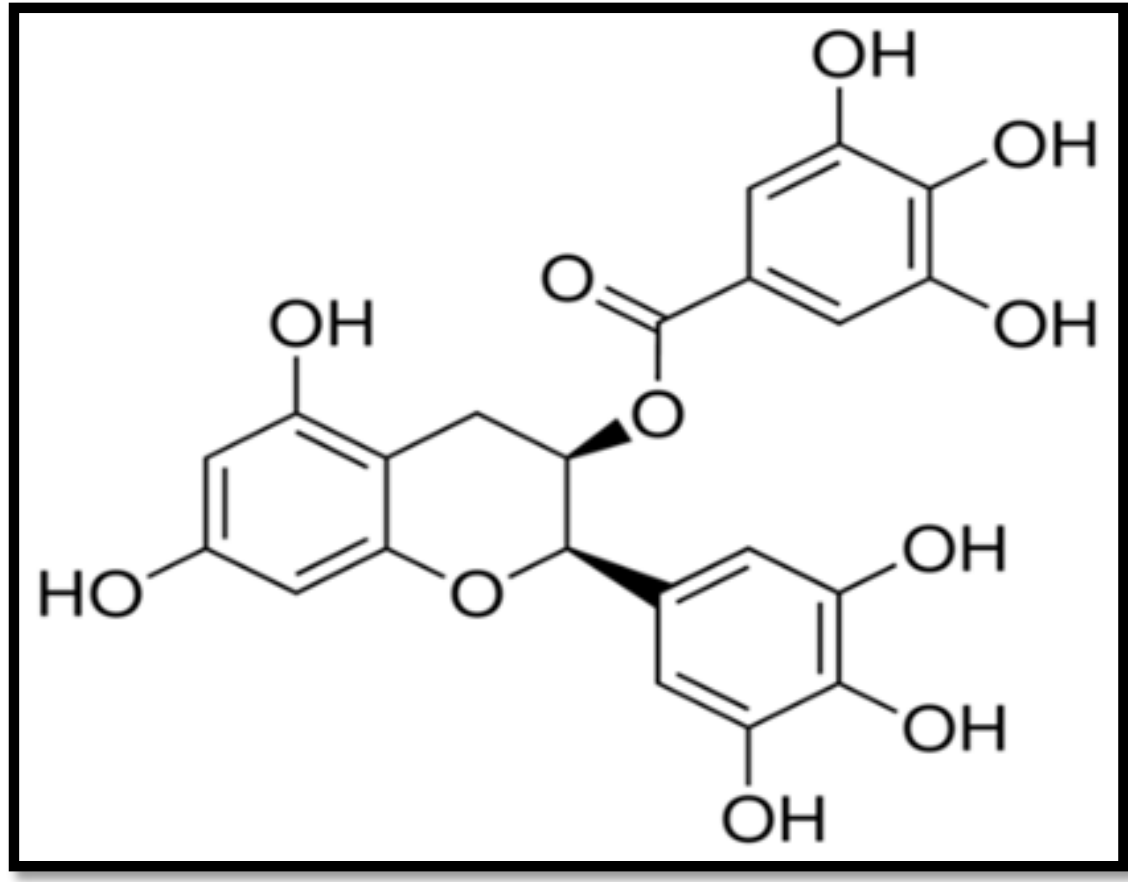

A pasta à base de EGCG foi preparada de acordo com estudos prévios do nosso grupo de pesquisa (Ferreira, 2013; Ferreira, 2015). O polietilenoglicol 400 (PEG 400 - Galena Química e Farmacêutica Ltda. - Campinas - SP - Brasil) foi utilizado como veículo para manter a EGCG por tempo prolongado no canal radicular, sem alterar suas propriedades físico-químicas (Ferreira, 2013). Também, foi acrescido o óxido de zinco (OZ - S.S. White Artigos Dentários Ltda.- Rio de Janeiro RJ - Brasil) para fornecer radiopacidade. A pasta, contendo EGCG na concentração de $1 \mathrm{mg} / \mathrm{mL}$ (Schmitz et al., 2005; Ferreira, 2015) foi acondicionada em tubetes, para permitir uso intracanal. A EGCG veiculada em água destilada e deionizada (proveniente da osmose reversa - Laboratório de Ciências Farmacêuticas, da Faculdade de Ciências Farmacêuticas de Ribeirão Preto da Universidade de São Paulo), também foi avaliada, por ser a água o solvente preconizado nas especificações do fabricante da EGCG (Anexo B).

$\mathrm{O}$ tratamento endodôntico realizado em duas sessões com a pasta à base de EGCG foi comparado com o mesmo tratamento utilizando uma pasta à base de hidróxido de cálcio (Calen ${ }^{\circledR}$ - S.S. White Artigos Dentários Ltda. - Rio de Janeiro - RJ - Brasil) e com o tratamento endodôntico realizado em sessão única, sem utilização 
de curativo de demora. A pasta Calen é composta de hidróxido de cálcio, óxido de zinco p.a., colofônia e polietilenoglicol 400 (veículo).

Os grupos experimentais a concentração de EGCG, tratamentos realizados e número de dentes estão listados na Tabela 1.

Tabela 1- Tratamentos realizados no presente estudo e distribuição do número de dentes para cada grupo.

\begin{tabular}{cllc}
\hline Grupo & \multicolumn{1}{c}{ Tratamento } & Número de dentes & Concentração de EGCG \\
\hline I & Pasta à base de EGCG & 10 dentes (20 raízes) & $1 \mathrm{mg} / \mathrm{mL}$ \\
II & EGCG em veículo aquoso & 10 dentes (20 raízes) & $1 \mathrm{mg} / \mathrm{mL}$ \\
III & Pasta à base de $\mathrm{CaOH}_{2}$ & 10 dentes (20 raízes) & - \\
IV & Sessão única & 10 dentes (20 raízes) & - \\
\hline
\end{tabular}

EGCG: Epigalocatequina-3-galato

$\mathrm{CaOH} 2$ : Hidróxido de cálcio

\subsection{Procedimentos Operatórios}

O protocolo experimental foi realizado com base nas normas da International Organization for Standardization (ISO) n 7405:2008). No presente estudo, os cães foram acompanhados por um único período de 120 dias, visando restringir o número de animais ao mínimo indispensável para obtenção de resultados conclusivos, em atendimento à Lei Brasileira $n^{\circ} 11.794$ (Art. $11, \S^{\circ}$ ) e às recomendações da CEUA/FORP-USP.

Foram utilizados os $2^{\circ \text { os }}$ e $3^{\text {os }}$ pré-molares superiores e os $2^{\circ s}, 3^{\circ s}$ e $4^{\circ s}$ prémolares inferiores permanentes, totalizando 40 dentes (80 raízes). Todos os dentes apresentavam-se hígidos, com 2 raízes e 2 canais radiculares separados (mesial e distal), retos e com rizogênese completa, comprovada radiograficamente.

Para a realização dos procedimentos operatórios foi realizada a anestesia inalatória dos animais sob os cuidados de um médico veterinário. Na fase de tranquilização, os animais foram pré-anestesiados, por meio de injeção por via endovenosa de acepromazina (Acepran 0,2\% - Vetnil Indústria e Comércio de Produtos Veterinários Ltda - Louveira - SP - Brasil), na dosagem de $0,11 \mathrm{mg} / \mathrm{kg}$ de peso, 15 minutos antes do ato operatório. Na fase de indução foi aplicado zolazepam (Zoletil 50 Virbac do Brasil - São Paulo - SP - Brasil), na dosagem de $3 \mathrm{mg} / \mathrm{kg}$ de peso, por via endovenosa, para posterior passagem da sonda endotraqueal, necessária para a realização da anestesia inalatória. Após a intubação com sonda 
endotraqueal, a fase de manutenção da anestesia foi realizada com isoflurano (Abbott Laborat. do Brasil Ltda. - Rio de Janeiro - RJ - Brasil), na concentração de 1,5 a 2,5\% juntamente com oxigênio, utilizando o aparelho para anestesia inalatória (Takaoka KT-20 - Biocom Tecnologia - São Paulo - SP - Brasil), até indução do efeito. Durante todo ato operatório, os animais foram mantidos com solução isotônica de cloreto de sódio a 0,9\% (Glicolabor Indústria Farmacêutica Ltda. - Ribeirão Preto SP - Brasil), sob monitoramento cardiorrespiratório realizado com auxílio de oxímetro de pulso veterinário (Edan ZEH100B -Sistem Biomédica - Yucatan - México). Após a realização dos procedimentos operatórios os animais receberam analgésico (Cloridrato de Tramadol, Medelly S/A - Campinas -Brasil), na dosagem de $3 \mathrm{mg} / \mathrm{kg}$ de peso, por via endovenosa, a cada 12 horas, durante 2 dias.

0 exame radiográfico periapical dos dentes foi realizado com filmes periapicais no 2, ultra-rápidos (Eastman Kodak Company - Rochester - NY - EUA), pela técnica da bissetriz, utilizando o aparelho de raios- $X$ odontológico (Heliodent Siemens - NY - EUA), com $60 \mathrm{kVp}$ e $10 \mathrm{~mA}$ e tempo de exposição de 1 segundo. As radiografias foram reveladas em câmara escura pelo método tempo/temperatura.

Todo o instrumental utilizado nos procedimentos operatórios foi esterilizado em autoclave a $121^{\circ} \mathrm{C}$, por 20 minutos (Souza-Gugelmin et al., 2005) e os procedimentos operatórios foram realizados por um único profissional, CirurgiãoDentista, especialista e com ampla experiência em experimentação animal. Após a realização de profilaxia e raspagem dental, foi realizada a abertura coronária pela face oclusal utilizando pontas esféricas diamantadas nº 1015 (K.G. Sorensen - São Paulo - SP - Brasil) montadas em motor de alta rotação, refrigeradas com ar/água, complementadas com pontas diamantadas cônicas de extremidade inativa $\left(n^{\circ} 3083\right.$ KG Sorensen).

Após a abertura a polpa foi removida com uma lima tipo Hedströen e o dente foi mantido aberto por 7 dias para que houvesse a contaminação por microorganismos bucais. Após o período de 7 dias os dentes foram selados provisoriamente com mechas de algodão e cimento de óxido de zinco e eugenol $\left(\right.$ IRM $^{\circledR}$ - Dentsply Industria e Comércio Ltda. - Petrópolis - Brasil), para que pudesse ser formado um ambiente de anaerobiose, após a contaminação bacteriana, e consequentemente, a formação de lesão periapical (Leonardo et al., 1993). 
Após 45 a 60 dias da indução das lesões periapicais, que foi evidenciada radiograficamente, o tratamento endodôntico iniciou-se sob isolamento absoluto com dique de borracha e anti-sepsia com digluconato de clorexidina a 2,0\% (Periogard Colgate - Palmolive Indústria Ltda.). O cimento provisório e a mecha de algodão da câmara pulpar foram removidos com pontas diamantadas esféricas e os canais radiculares submetidos à neutralização imediata do conteúdo séptico-tóxico aplicando o princípio coroa/ápice (Leonardo; 2005), empregando instrumentos de níquel-titânio do Sistema Protaper Universal (Dentsply/Maillefer), introduzindo os instrumentos com diminuição gradativa de diâmetros, acompanhados pela irrigação/aspiração e nova inundação com solução de hipoclorito de sódio a 2,5\%.

Realizada a odontometria e determinado o Comprimento Real de Trabalho (CRT), o forame apical foi alargado mecanicamente com limas tipo $K$ de $n^{\circ} 15,20$ e 25, sendo esta última lima designada de Instrumento Apical Foraminal (IAF), utilizada para padronização do diâmetro de abertura apical dos dentes em estudo. Na mesma sessão foi realizado o preparo biomecânico, empregando instrumentos de níquel-titânio do Sistema Protaper Universal (Dentsply/Maillefer) até o CRT, estabelecido aproximadamente a $1 \mathrm{~mm}$ aquém do ápice radiográfico. Após a utilização de cada instrumento, foi realizada a irrigação/aspiração/inundação dos canais radiculares com solução de hipoclorito de sódio a 2,5\%.

Terminado o preparo biomecânico, uma lima tipo K no 25 (IAF) foi novamente utilizada em todo $C R T$, para remoção de possíveis raspas de dentina e resíduos acumulados na região do forame apical, em decorrência do preparo biomecânico. Após nova irrigação e aspiração, os canais radiculares foram secos com pontas de papel absorvente esterilizadas e, a seguir, inundados com solução de ácido etilenodiaminotetracético (EDTA), tamponado em pH 7,4 até o CRT e agitado por 3 minutos com lima. Após irrigação copiosa com solução de hipoclorito de sódio a $1 \%$ para neutralização do EDTA, foi realizada a secagem por aspiração e uso de pontas de papel absorvente, de calibre compatível com o diâmetro do último instrumento utilizado no CRT. A seguir, os procedimentos foram realizados de acordo com a técnica preconizada em cada grupo.

Nos grupos I a III, após o preparo biomecânico, o curativo de demora com cada material (contido em tubetes) foi aplicado na medida de $1 \mathrm{~mm}$ além do CRT, 
com a finalidade de promover um pequeno extravasamento e proporcionar seu contato com a superfície apical externa, este procedimento foi realizado com 0 auxílio de seringa rosqueável ML (S.S. White Artigos Dentários Ltda. - Rio de Janeiro - Brasil) e agulha longa 27G (Septoject XL - Septodont - França) sendo realizadas tomadas radiográficas para a comprovação do extravasamento. Em seguida, foi realizado selamento coronário provisório com mecha de algodão esterilizada e cimento à base de óxido de zinco e eugenol (OZ - S.S. White Artigos Dentários Ltda. - Rio de Janeiro - RJ - Brasil). Após 14 dias da aplicação do curativo de demora, sob nova anestesia geral, isolamento absoluto e anti-sepsia do campo operatório, foi removido o selamento provisório conforme descrito anteriormente e o curativo de demora mediante copiosa irrigação/aspiração com hipoclorito de sódio a 2,5\%, coadjuvada com o último instrumento utilizado na confecção do batente apical no CRT. A seguir, os canais radiculares foram secos com pontas de papel absorvente esterilizadas e inundados com EDTA até o CRT e agitado por 3 minutos com o IAF. Após irrigação copiosa com solução de hipoclorito de sódio a $1 \%$ para neutralização do EDTA, foi realizada nova secagem dos canais com pontas de papel absorvente esterilizadas. Para a obturação dos canais, os cones de guta-percha (principal e auxiliares) foram submetidos à desinfecção com solução de clorexidina a $2 \%$. Após a seleção do cone, foi realizada comprovação radiográfica da escolha clínica do mesmo. Seguindo a técnica clássica modificada de obturação, o cone principal foi envolto no cimento obturador AH Plus (Dentsply/Detrey - Kontstanz, - Germany) em toda sua extensão e levado para o interior do canal radicular com um único movimento. A seguir, foi feita a condensação lateral ativa com o auxílio de espaçador digital e cones de guta-percha auxiliares. Após o corte do excesso da obturação e condensação vertical, as câmaras pulpares foram limpas com mechas de algodão esterilizadas umedecidas em álcool, sendo os dentes restaurados com amálgama de prata (Velvalloy - S.S.White Art. Dent. Ltda.) condensado sobre uma base de cimento de ionômero de vidro (Vidrion F - S.S.White Art. Dent. Ltda).

No grupo IV, não foi aplicado curativo de demora e a obturação foi realizada após o preparo biomecânico, em única sessão, conforme descrito acima.

Decorrido o período experimental de aproximadamente 120 dias, foi realizado novo exame radiográfico periapical, e os animais foram submetidos à 
eutanásia por sobredose anestésica, de acordo com as Diretrizes da prática de Eutanásia do CONCEA do Ministério da Ciência e Tecnologia. Inicialmente, foi realizada a anestesia por meio de injeção por via endovenosa de acepromazina (Acepran 0,2\%), na dosagem de 0,2 mg/kg de peso. Após 15 minutos, foi realizada a anestesia com Tiopental (Thionembutal - Abbot Laboratórios do Brasil Ltda. - Rio de Janeiro - RJ - Brasil) endovenoso, na dosagem de 25 mg/kg de peso. Em seguida, foi realizada a eutanásia com cloreto de potássio a 20\%, via endovenosa, na dosagem de $100 \mathrm{mg} / \mathrm{kg}$ de peso, injetado lentamente.

\subsection{Análise radiográfica}

As imagens radiográficas, obtidas antes e 120 dias após o tratamento endodôntico foram digitalizadas e transferidas para o programa Image J $1.28 \mathrm{u}$ (National Institutes of Health - Califórnia - EUA) para mensuração das áreas radiolúcidas periapicais. A delimitação e a medida da área radiolúcida sugestiva de lesão periapical presente em cada raiz foi determinada em $\mathrm{mm}^{2}$.

Foram incluídas áreas radiolúcidas sugestivas de lesões periapicais sendo excluídos osso alveolar e estruturas dentais radiopacas como representada na Figura 2. O percentual de redução da área radiolúcida foi obtido para cada raiz.

Figura 2. Imagem representativa da radiografia prévia ao tratamento endodôntico ilustrando a técnica utilizada na mensuração da área radiolúcida periapical (linha amarela).

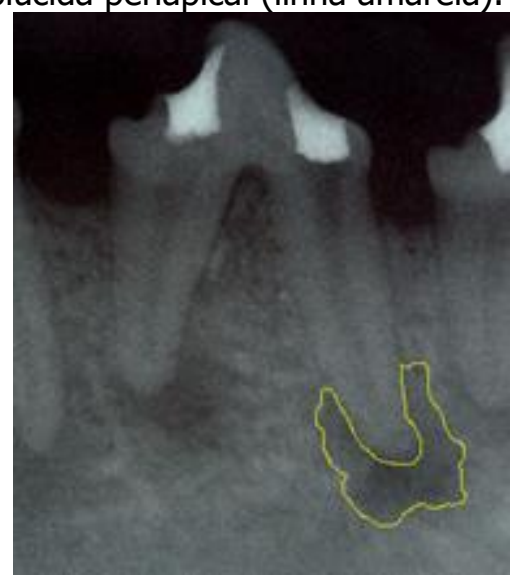

\subsection{Processamento histotécnico e análise histopatológica}

Após a eutanásia dos animais, as maxilas e mandíbulas foram dissecadas, com auxílio de um bisturi, reduzidas em seu volume e lavadas em água corrente. 
Para facilitar o processamento histotécnico, as peças foram seccionadas utilizando discos diamantados, sob constante refrigeração com água obtendo-se blocos das peças anatômicas contendo os dentes individualmente.

As peças foram submetidas à fixação em solução de formol tamponado a $10 \%$, por 48 horas, à temperatura ambiente. Posteriormente, as peças foram imersas em um recipiente de vidro contendo uma solução à base de ácido etilenodiaminotetracético (EDTA Disodium Salt Dihydrate - Merck - Darmstadt Alemanha) a $10 \%$ e submetidas à desmineralização acelerada pelo Vortex tipo Agitador KLINE NT151 (Novatecnica ${ }^{\circledR}$ - Piracicaba - São Paulo - Brasil). As peças foram imersas em solução desmineralizadora de EDTA a $22 \%$ e colocadas em agitação orbital a $70 \%, 8$ horas por dia. No intervalo entre os dias, as peças permaneceram na solução de EDTA sem agitação, na temperatura ambiente. A solução desmineralizadora foi trocada semanalmente. A completa descalcificação das amostras, avaliada por meio da penetração de uma agulha para verificação da sua consistência, foi obtida aproximadamente em 30 dias.

Concluída a desmineralização, as peças foram neutralizadas em solução de sulfato de sódio a 5\% (Sulfato de Sódio Anhidro - J.T.Baker - Fisher Sci. - USA) por 24 horas, lavadas em água corrente por 8 horas, desidratadas em concentrações crescentes de álcool (Álcohol Etílico Absoluto Anhidro ${ }^{\circledR}$-J.T.Baker), imersas em álcool xilol 50\% por 30 min, diafanizadas em xilol 100\% (Xylo ${ }^{\circledR}$ - Merck Alemanha), trocado a cada hora por 3 vezes, e inclusas em parafina (Histosec ${ }^{\circledR}$ Pastillen - Merck - Alemanha), de acordo com a rotina histotécnica. Os blocos contendo as raízes individualizadas foram reduzidos pela microtomia a cortes seriados longitudinais com $5 \mu \mathrm{m}$ de espessura em sentido mesio-distal.

Os cortes foram corados com hematoxilina e eosina (HE). Para a avaliação histopatológica, as lâminas foram observadas no microscópio AXIO IMAGER.M1 (Zeiss, Gottingen - Alemanha) operando em modo convencional e modo fluorescência (Leica DMR - Leica Microsystem Wetzlar Gmbh - Wetzlar - Alemanha). Os espécimes foram classificados de acordo com os seguintes parâmetros (Hidalgo et al., 2016): infiltrado inflamatório (ausente, suave, moderado ou severo), espessura do ligamento periodontal (normal, levemente aumentado, moderadamente 
aumentado ou severamente aumentado) e reabsorção de tecidos mineralizados, cemento e osso alveolar (ausente ou presente).

\subsection{Análise estatística}

Os resultados foram analisados utilizando o programa estatístico Graph Pad Prism 4 (Graph Pad Software Inc, San Diego, CA, EUA). Os valores finais obtidos na avaliação radiográfica foram analisados por meio da análise de variância (ANOVA) e pós teste de TukeyOs parâmetros histopatológicos foram analisados utilizando o teste chi-quadrado $\left(x^{2}\right)$ e em resultados dicotômicos, o teste exato de Fisher. Em ambas análises foi adotado nível de significância de 5\%. 

4. Resultados 



\subsection{Análise radiográfica}

De acordo com os resultados radiográficos, aos 120 dias após tratamento endodôntico, o percentual médio de redução da área radiolúcida periapical ( \pm erro padrão da média) no grupo tratado com pasta à base de EGCG foi de 59,95\% $( \pm 8,023)$ e de EGCG em veículo aquoso foi de $64,57 \%( \pm 7,514)$. No grupo tratado com pasta à base de hidróxido de cálcio observou-se uma redução de 58,65\% $( \pm 6,192)$ e no grupo tratado em sessão única, verificou-se redução de 19,49\% $( \pm 2,881)$ na área radiolúcida periapical. Os percentuais médios de redução da área radiolúcida periapical de cada grupo encontram-se na figura 3.

$\mathrm{Na}$ análise estatística verificou-se que os percentuais de redução da área radiolúcida foram semelhantes nos três grupos onde foi utilizado curativo de demora, com EGCG ou $\mathrm{CaOH}_{2}(p>0,05)$ e que estes resultaram em redução superior ao grupo tratado em sessão única $(p<0,01)$.

Figura 3. Percentual de redução na imagem radiolúcida periapical após a realização do tratamento endodôntico com pasta à base de EGCG, EGCG em veículo aquoso, pasta à base de hidróxido de cálcio ou sessão única ns= diferença não significante.

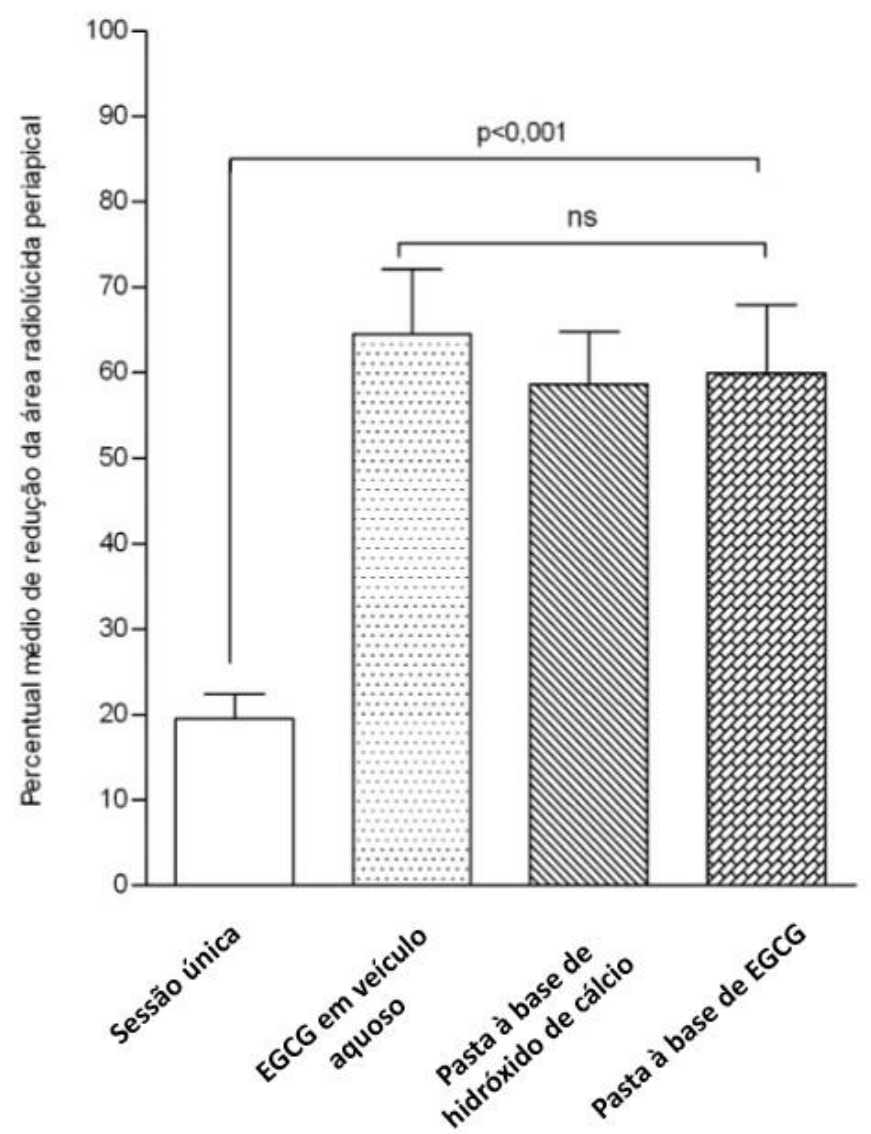




\subsection{Análise histopatológica}

De um total de 80 raízes inicialmente tratadas, 26 raízes foram perdidas durante 0 processamento histotécnico. Restaram 12 raízes para o grupo experimental EGCG em veículo aquoso, 20 raízes para o grupo pasta à base de EGCG, 11 raízes para o grupo tratado com pasta à base de hidróxido de cálcio e 11 raízes para o tratamento em sessão única. Os percentuais médios encontrados em cada escore de cada parâmetro encontram-se na Tabela 2.

\section{- Grupo I: Pasta à base de EGCG}

Pode-se observar ocorrência do processo de reparação dos tecidos apicais e periapicais (cemento, ligamento periodontal e osso alveolar), caracterizada por ausência de infiltrado inflamatório ou presença suave de poucas células mononucleares. O ligamento periodontal encontrava-se normal ou suavemente aumentado, em consequência do processo de reparação por neoformação óssea na lesão periapical anteriormente existente. A superfície externa e interna do cemento, que na lesão periapical apresentavam-se reabsorvidas, estavam reparadas por deposição de tecido mineralizado, muitas vezes selando a abertura do forame apical. As lacunas de cementócitos, anteriormente aumentadas em consequência da infecção, apresentavam-se reparadas e com retorno de cementócitos. Neste grupo verificou-se presença marcante de fibras colágenas e vasos sanguíneos na região periapical em reparação. A fibras colágenas partiam da superfície do cemento, em reparação, em direção à região periapical e exibiram forte fluorescência verde quando avaliadas em microscopia de fluorescência (Tabela 2 e Figura 5).

\section{- GrupoII: EGCG em veículo aquoso}

Neste grupo, pode-se observar características histopatológicas semelhantes ao grupo anterior com ocorrência de processo de reparação apical e periapical caracterizado por presença de fibroblastos, fibras colágenas e vasos sanguíneos, com ausência ou suave presença de células inflamatórias de natureza mononuclear. 0 ligamento periodontal, em processo de reparação, estava suavemente ou 
moderadamente aumentado em alguns espécimes, em consequência do processo de reparação em evolução. Pode-se observar a formação de tecido mineralizado reparando as áreas anteriormente reabsorvidas no osso alveolar ao redor da lesão, forame apical e superfície externa e interna do cemento. Na microscopia de fluorescência foi possível observar a reinserção de fibras colágenas na superfície cementária e ligamento periodontal, caracterizando processo de reparação em evolução (Tabela 2 e Figura 6).

\section{- Grupo III: Pasta à base de hidróxido de cálcio}

Neste grupo também foi observado ocorrência de processo de reparação em evolução, semelhante aos grupos anteriores. Observou-se presença de fibas colágenas e vasos sanguíneos neofromados, presença de infiltrado inflamatório suave e redução do espaço do ligamento periodontal. Nenhuma raiz apresentou ligamento periodontal severamente aumentado e o formame apical apresentou selamento biológico. As de lacunas de reabsorção cementárias, internas e externas, também estavam em processo de reparação, sendo revestidas por tecido mineralizado neoformado e fibras colágenas mais delicadas, quando comparadas aos grupos anteriores, melhor visualizadas na microscoia de fluorescência, partindo do cemento em direção à região periapical (Tabela 2 e Figura 7).

\section{- Grupo IV: Sessão Única}

No grupo submetido ao tratamento endodôntico em uma sessão única não verificou-se processo de reparo apical e periapical como nos grupos anteriores. Observou-se persistência de lesão periapical, caracterizada pela presença de infiltrado inflamatório de natureza mista, com células mono e polimorfonucleares. 0 ligamento periodontal apresentava-se severamente aumentado na maioria dos espeécimes. Observou-se presença de reabsorção ativa dos tecidos mineralizados, caracterizada pela presença de lacunas de reabsorção na superfície externa e interna do cemento, com alargamento dos espaços dos osteócitos e desaparecimento dos mesmos mostrando que esta técnica não permitiu o reparo ósseo e cementário. $A$ 
microscopia de fluorescência não revelou presença significativa de fibras colágenas neoformadas na superfície cementária ou mesmo no espaço periodontal (Tabela 2 e Figura 8).

A análise estatística mostrou que os grupos que receberam aplicação de curativo de demora com EGCG ou hidróxido de cálcio, apresentaram semelhança em todos os parâmetros histológicos avaliados. Por outro lado, o tratamento em sessão única resultou em maior espessura do ligamento periodontal $(p<0,001)$, presença de infiltrado inflamatório moderado ou severo $(p<0,01)$ e persistência de reabsorção óssea e cementária $(p<0,0001)$. 
Tabela 2. Distribuição de número de raízes (percentual) encontradas em cada parâmetro de análise histopatológica e análise estatística.

\begin{tabular}{|c|c|c|c|c|c|}
\hline \multirow[b]{2}{*}{$\begin{array}{c}\text { Parâmetro } \\
\text { histopatológico }\end{array}$} & \multirow[b]{2}{*}{ Escores } & \multicolumn{4}{|c|}{ Protocolo de Tratamento } \\
\hline & & $\begin{array}{c}\text { Pasta à } \\
\text { base de } \\
\text { EGCG } \\
\text { n (\%) }\end{array}$ & $\begin{array}{c}\text { EGCG em } \\
\text { veículo } \\
\text { aquoso } \\
\text { n (\%) }\end{array}$ & $\begin{array}{c}\text { Pasta à base } \\
\text { de hidróxido } \\
\text { de cálcio } \\
\text { n (\%) }\end{array}$ & $\begin{array}{c}\text { Tratamento } \\
\text { em sessão } \\
\text { única } \\
\text { n (\%) }\end{array}$ \\
\hline \multirow{5}{*}{$\begin{array}{c}\text { Infiltrado } \\
\text { Inflamatório }\end{array}$} & Ausente & $8(40,0)$ & $7(58,33)$ & $8(72,72)$ & $0(0,0)$ \\
\hline & Suave & $11(55,0)$ & $4(33,33)$ & $2(18,18)$ & $2(16,66)$ \\
\hline & Moderado & $0(0,0)$ & $1(8,33)$ & $1(9,09)$ & $3(25,0)$ \\
\hline & Severo & $1(5,0)$ & $0(0,0)$ & $0(0,0)$ & $7(58,33)$ \\
\hline & Análise estatística & a & a & a & b \\
\hline \multirow{5}{*}{$\begin{array}{c}\text { Espessura do } \\
\text { ligamento } \\
\text { periodontal }\end{array}$} & Normal & $3(15,0)$ & $0(0,0)$ & $1(9,09)$ & $0(0,0)$ \\
\hline & $\begin{array}{l}\text { Levemente } \\
\text { aumentado }\end{array}$ & $6(30,0)$ & $1(8,33)$ & $5(45,45)$ & $1(8,33)$ \\
\hline & $\begin{array}{c}\text { Moderadamente } \\
\text { aumentado }\end{array}$ & $10(50,0)$ & $10(83,33)$ & $5(45,45)$ & $5(41,66)$ \\
\hline & $\begin{array}{c}\text { Severamente } \\
\text { aumentado }\end{array}$ & $1(5,0)$ & $1(8,33)$ & $0(0,0)$ & $6(50,0)$ \\
\hline & Análise estatística & $\mathbf{a}$ & $\mathbf{a}$ & $\mathbf{a}$ & b \\
\hline Reabsorção & Ausente & $15(75,0)$ & $7(58,33)$ & $6(54,54)$ & $2(16,0)$ \\
\hline dos tecidos & Presente & $5(25,0)$ & $5(41,66)$ & $5(45,45)$ & $10(83,33)$ \\
\hline mineralizados & Análise estatística & $\mathbf{a}$ & $\mathbf{a}$ & $\mathbf{a}$ & b \\
\hline
\end{tabular}

Letras diferentes indicam diferença estatisticamente significante $(p<0,05)$ de acordo com os testes de Fisher e $x^{2}$. 
Figura 5. Fotomicrografias representativas das regiões apical e periapical 120 dias após o tratamento endodôntico com pasta à base de EGCG, observadas em microscopia de luz convencional ( $A, C$ e $E)$ e de fluorescência $(B, D$ e $F)$ :

(A e B) Região apical e periapical em reparação com espaço do ligamento periodontal normal, cemento apical e osso alveolar com superfície regular ( $\mathrm{HE}, 5 \mathrm{X})$.

(C e D) Espaço do ligamento periodontal com presença de fibras colágenas e vasos sanguíneos, cemento apical e osso alveolar com superfície regular com deposição de tecido mineralizado neoforado (nc) (HE, 20X).

(E e F) Abundante deposição de fibras colágenas e vasos sanguíneos na região periapical (HE, 40X). 


\section{PASTA À BASE DE EGCG}
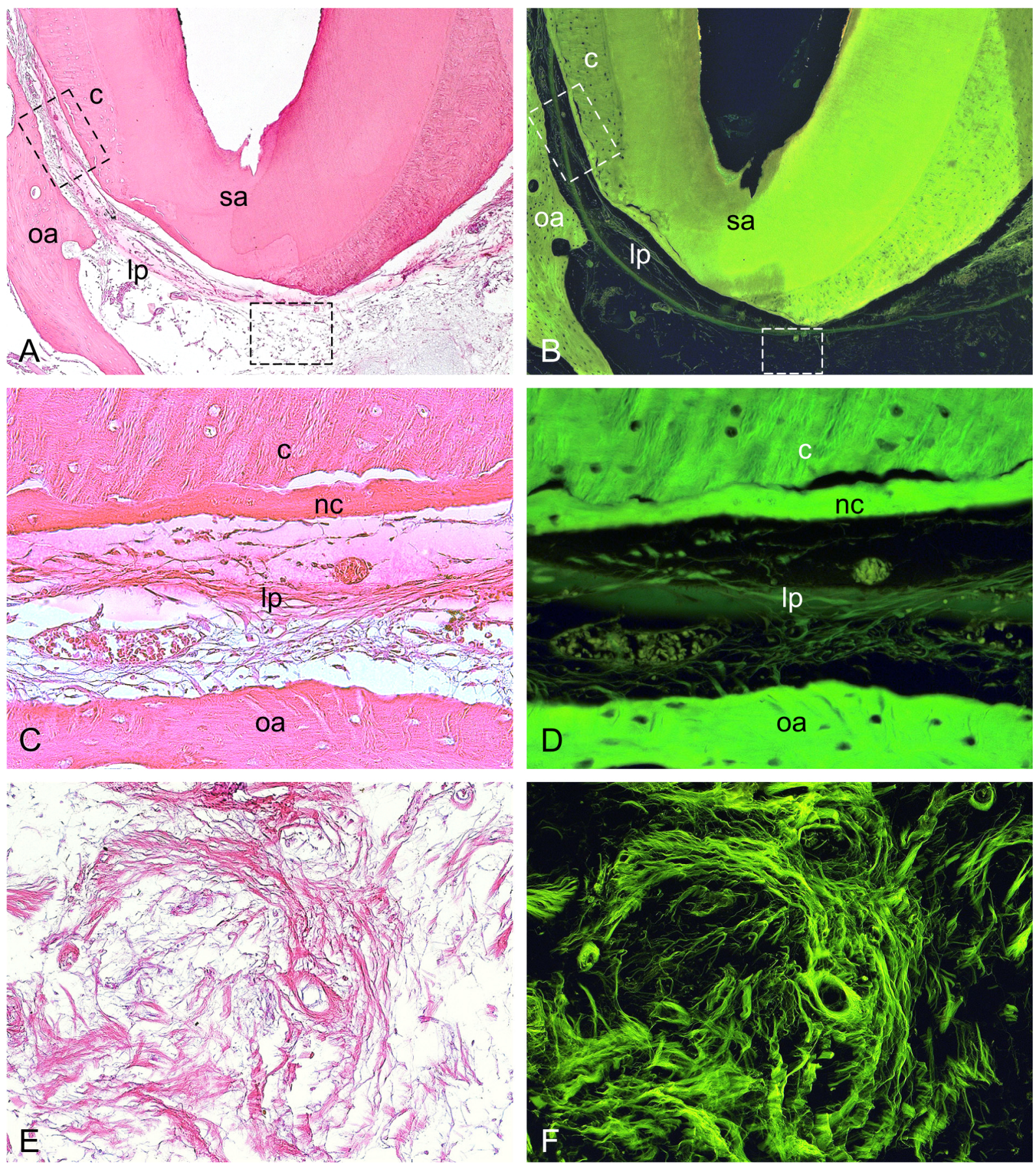
Figura 6. Fotomicrografias representativas da região apical e periapical aos 120 dias após o tratamento endodôntico com curativo de demora com EGCG veiculada em água, avaliadas em microscopia de luz convencional ( $A, C$ e $E)$ e de fluorescência ( $B, D$ e $F)$ :

(A e B) Região apical e periapical em reparação, cemento apical (c) e osso alveolar (ao) com superfície regular. Presença de fibras colágenas e vasos sanguíneos neoformados no espaço do ligamento periodontal (Ip) (HE, 5X).

(C e D) Região do forame apical reparada por tecido mineralizado (sa), deposição de cemento nas áreas externas e internas das lacunas de reabsorção (HE, 20X).

(E e F) Região periapical com abundante deposição de fibras colágenas na superfície cementária neoformada (nc), partindo em direção ao espaço do ligamento periodontal $(\mathrm{HE}, 40 \mathrm{X})$. 


\section{EGCG EM VEÍCULO AQUOSO}
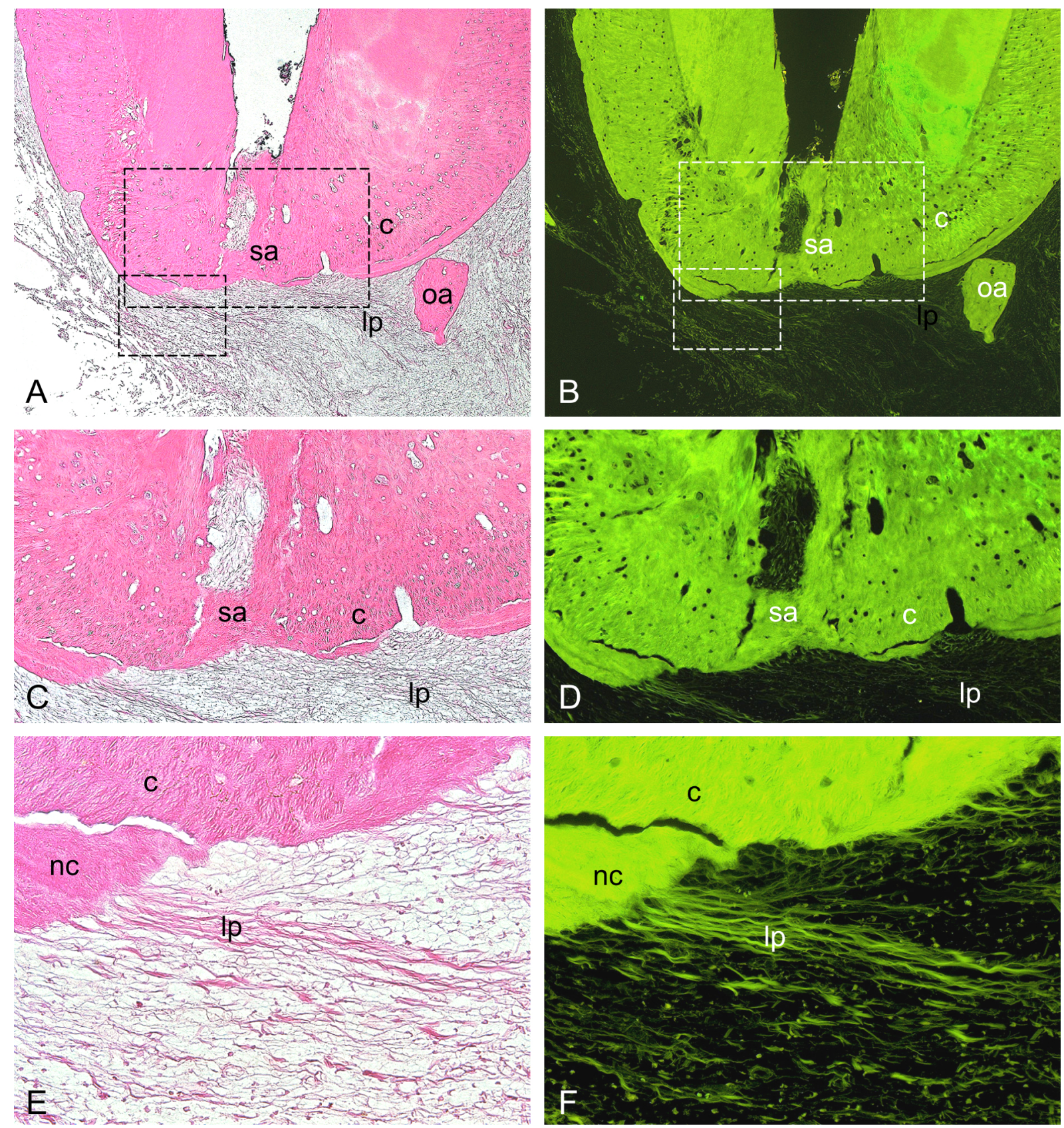
Figura 7. Fotomicrografias representativas da região apical e periapical aos 120 dias após o tratamento endodôntico realizado com curativo de demora com pasta à base de hidróxido de cálcio, sob microscopia de luz convencional ( $A, C$ e E) e de fluorescência (B, D e F):

(A e B) Região apical e periapical com espaço do ligamento periodontal em reparação, ausência de infiltrado inflamatório, cemento apical e osso alveolar reparados e selamento apical (sa) (HE, 5X).

(C e D) Região do forame apical reparada por deposição de tecido mineralizado (sa) e reparação das lacunas internas e superfície externa do cemento (HE, 20X).

(E e F) Ligamento periodontal com reinserção de fibras colágenas e proliferação de vasos sanguíneos (HE, 40X). 
PASTA À BASE DE HIDRÓXIDO DE CÁLCIO

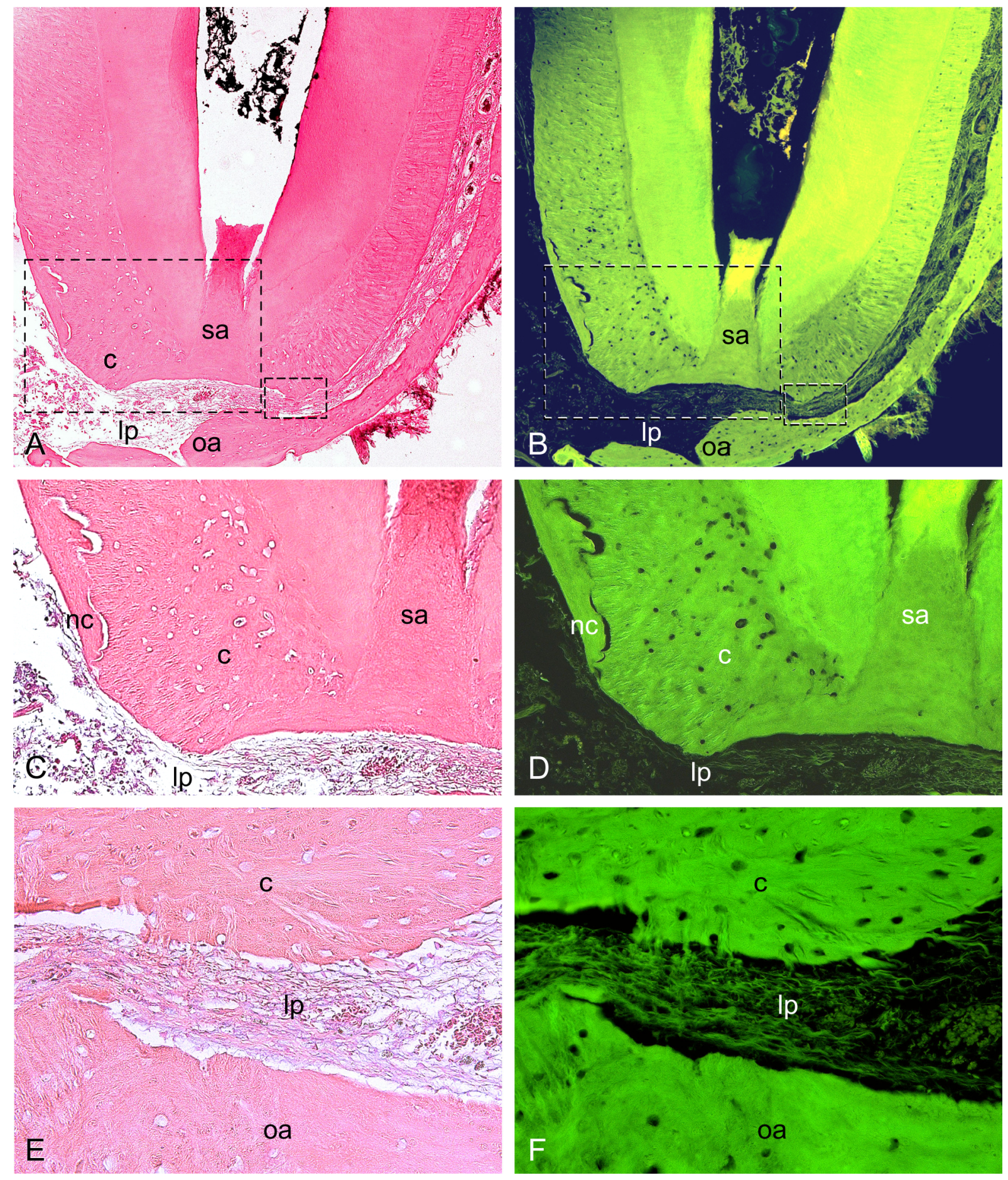


Figura 8. Fotomicrografias representativas da região apical e periapical aos 120 dias após realização do tratamento endodôntico em sessão única, observadas em microscopia de luz convencional ( $A, C$ e E) e de fluorescência ( $B, D$ e $F)$ :

(A e B) Região apical e periapical com presença de infamação e reabsorção, espaço do ligamento aumentado, ausência de selamento do forame apical, abundante infiltrado inflamatório (polimorfo e morfonucleares) e cemento apical e osso alveolar com superfície irregular caracterizada por áreas de reabsorção ativas ( $\mathrm{HE}$, $5 X)$.

(C e D) Cemento apical severamente reabsorvido na superfície externa e em suas lacunas internas e presença de infiltrado inflamatório (polimorfo e morfonucleares) (HE, 20X).

(E e F) Infiltrado inflamatório composto por neutrófilos e linfócitos (HE, 40X). 


\section{SESSÃO ÚNICA}
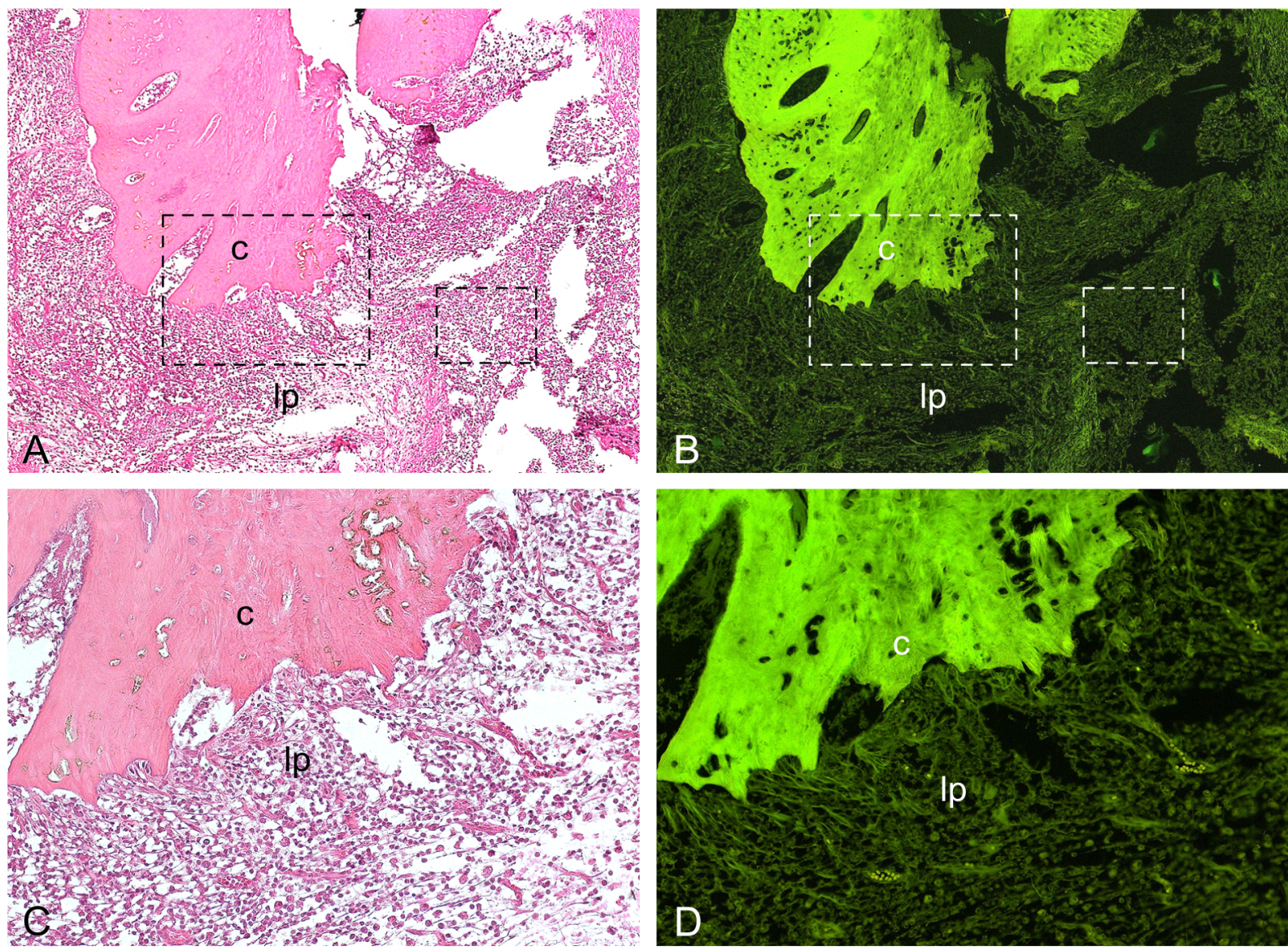

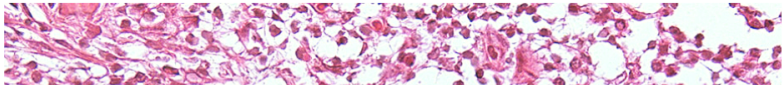

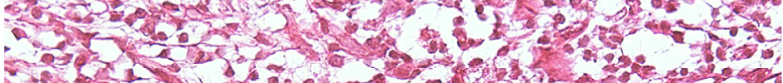
- Ir. 35.

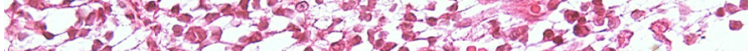

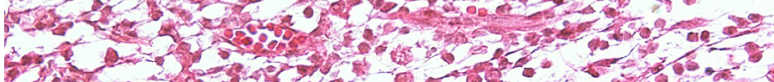
25 a

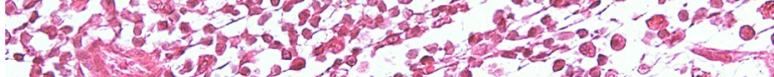

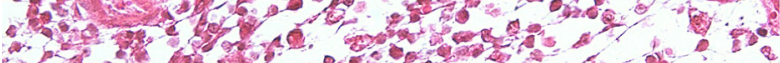

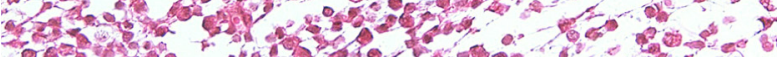
Fen

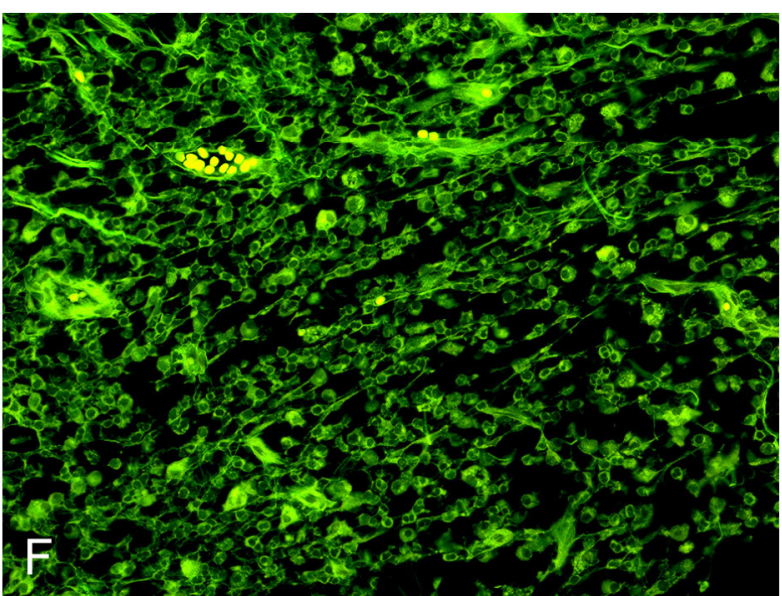





\section{Discussão}



O presente trabalho teve como objetivo avaliar a eficácia de uma nova formulação à base de Epigalocatequina-3-galato, derivada do chá verde, como curativo de demora utilizada durante o tratamento endodôntico de dentes de cães, com rizogênese completa e lesão periapical induzida experimentalmente. Sabe-se que a aplicação de curativo de demora com hidróxido de cálcio atualmente é o método que apresenta resposta reparadora tecidual satisfatória (Sjögren et al., 1991; Leonardo et al., 1995; Capik et al., 2005; Leonardo et al., 2006; Estrela et al., 2008; Hidalgo et al., 2016; De Queiroz et al., 2016). No entanto, estudos mostram que não é capaz de promover reparo tecidual completo em todos os casos e combater completamente a infecção existente nesses casos (Estrela et al., 1998; Chiniforuh et al., 2016; Dutta et al., 2017; Paikkatt et al., 2018). Assim, o desenvolvimento de uma nova formulação à base de um produto natural (EGCG) para utilização como curativo de demora em dentes necrosados com lesão periapical, poderia apresentar benefícios, em função de algumas propriedades biológicas que já efetuam papel antiinflamatório, anti-reabsorção, anti-oxidante, indutor de minerais e inibidor de metaloproteinases em diversas doenças sistêmicas (Zhao et al., 2012; Scalia et al., 2013; Reygaert e Jusufi, 2013, Rieghsecker et al., 2013; Aslan et al., 2014; Gundimeda et al., 2014; Zhou et al., 2014; Yoshino et al., 2014; Chen et al., 2014; Wang et al., 2014; Walker et al., 2015).

O uso tópico intracanal de uma pasta à base de EGCG, como curativo de demora durante o tratamento endodôntico, não havia sido proposto pela literatura. Um único estudo avaliou o efeito sistêmico da EGCG em lesões periapicais, administrada por via intra-peritoneal ( $80 \mathrm{mg} / \mathrm{kg}$ peso) em camundongos, onde verificou-se acentuada redução na extensão e severidade de lesões periapicais em dentes portadores de necrose pulpar (Lee et al., 2009). Sabe-se que o sucesso no tratamento desses casos depende da atuação essencialmente local realizada por meio da desinfeç̧ão do sistema de canais radiculares e região periapical, que abrigam os micro-organismos responsáveis pelo aparecimento e manutenção da doença (Kakehashi et al., 1965; Tronstad, 1992). Por esse motivo, o presente estudo avaliou uma formulação à base de EGCG para uso tópico que apresenta atividade antimicrobiana e compatibilidade tecidual, além de não alterar a cor dos dentes, e foi desenvolvida pelo nosso grupo de pesquisa (Ferreira, 2015). Estudos anteriores 
mostraram que a associação da EGCG com polietilenoglicol 400 e óxido de zinco oferecem viscosidade adequada para uso intracanal, mantendo suas propriedades físico-químicas, que são ativas inclusive em pH ácido encontrado na lesão periapical (Ferreira, 2013).

Atualmente, muitos extratos de plantas contendo polifenóis biologicamente ativos vem sendo incorporados em formulações cosméticas ou farmacêuticas com diferentes finalidades. No entanto, o preparo de formulações para uso tópico é delicado pois os polifenóis naturais não apresentam estabilidade ao longo do tempo, sendo muito sensíveis aos fatores ambientais, incluindo condições físico-químicas e biológicas. Estes podem oxidar rapidamente, o que leva ao aparecimento gradual de coloração castanha e indesejável, ou sofrer perda considerável de sua atividade (Munin e Edwards-Lévy, 2011). Ainda, estudos tem revelado que as múltiplas funções e mecanismos exercidos pelos compostos fenólicos no organismo estão relacionados não apenas à sua ação antioxidante, antimicrobiana, antiinflamatória, antitumoral e reparadora diretas, mas também à habilidade dessas substâncias de se ligarem a proteínas, receptores celulares e transportadores de membrana, podendo influenciar a expressão gênica, sinalização e adesão celular (Kroow e Williamson, 2005; Silva et al., 2010). Tais características fazem com que tais compostos possam exercer variadas funções no organismo humano (Giada e Mancini Filho, 2006). Assim, o desenvolvimento de novas formulações à base de extratos naturais visando avaliar potenciais aplicações no tratamento de doenças, como no presente estudo, devem incluir não apenas a análise de suas propriedades físico-químicas, mas também de seus possíveis efeitos biológicos (Reto et al., 2007).

$\mathrm{Na}$ avaliação radiográfica do presente estudo, o uso da nova formulação de EGCG (veiculada em água e PEG 400) resultou em redução das áreas radiolúcidas sugestivas de lesão periapical semelhante ao curativo de demora realizado com pasta à base de hidróxido de cálcio (Pasta Calen). Os grupos tratados com EGCG e hidróxido de cálcio apresentaram maior percentual de redução dessas áreas quando comparados ao grupo tratado em uma única sessão. A radiografia periapical foi utilizada por ser o método mais comumente utilizado para a avaliação da presença de lesão periapical pelos cirurgiões dentistas e especialistas em função do menor custo e menor dose de radiação. Ainda, esta análise radiográfica, embora apresente 
desvantagens da sobreposição de imagens, foi acompanhada da avaliação histopatológica que é considerada o padrão ouro para a avaliação da resposta tecidual do hospedeiro (De Rossi et al., 2007).

Na análise histopatológica, o grupo tratado em sessão única não apresentou processo de reparação apical e periapical, ao contrário, apresentou persistência de lesão periapical caracterizada pela presença de infiltrado inflamatório, reabsorção óssea e cementária e espessamento do ligamento periodontal. Por outro lado, os grupos tratados com pasta à base de hidróxido de cálcio, pasta à base de EGCG e EGCG em veículo aquoso apresentaram processo de reparo nos tecidos apicais e periapicais. Em muitos casos observou-se selamento apical nos grupos onde o curativo de demora foi utilizado. Embora nenhum estudo tenha avaliado o efeito da EGCG no reparo de lesões periapicais, nossos resultados estão de acordo com o observado em estudos radiográficos, histopatológicos e até microbiológicos que mostram reparação de lesões tratadas com o uso de hidróxido de cálcio e manutenção de lesão periapical em dentes obturados em sessão única (Leonardo et al., 1994; Leonardo et al., 1995; De Rossi et al., 2005; Hidalgo et al., 2016). Uma vez que a formulação testada proporcionou reparo tecidual semelhante ao encontrado no grupo tratado com hidróxido de cálcio, e já apresentou resultados adequados em testes fisico-químicos, de compatibilidade tecidual e não altera a cor da coroa dental, sugere-se sua possível utilização como medicação intracanal.

Embora no presente estudo tenhamos avaliado a ação da EGCG sobre o reparo tecidual, esta substância foi previamente proposta na terapia endodôntica, para atuar como agente irrigador dos canais radiculares durante o preparo químicomecânico (Prabhakar et al., 2010; Lee e Tan, 2015; Ferreira, 2015; Pheenithicharoenkul e Panichuttra 2016). Quando utilizada como solução irrigadora, além de apresentar ação antimicrobiana contra patógenos endodônticos (Prabhakar et al., 2010; Lee e Tan, 2015), a EGCG aumenta significativamente a força de adesão do cimento obturador às paredes do canal radicular (Pheenithicharoenkul e Panichuttra 2016; Yu et al., 2017) por apresentar forte ação anti-oxidante, capaz de neutralizar o hipoclorito de sódio ( $\mathrm{NaOCl}$ ) residual e oxigênio, e também por inibir a atividade proteolítica das metaloproteinases de matriz (MMPs) (Yu et al., 2017). 
As MMPs são uma família de endopeptidases zinco-dependentes, relacionadas com a função e estrutura dos tecidos por atuarem principalmente na degradação de componentes proteicos da matriz extracelular (ECM), incluindo as matrizes dentinária e óssea (Everts et al., 1992; Snoek-Van Beurden e Von Den Hoff, 2005; Tsuji et al., 2009; Kupai et al., 2010). As MMPs estão presentes no interior de células inflamatórias, porém, são mais frequentemente encontradas isoladas e na superfície celular ou no interior da matriz extracelular (Nagase e Woessner, 1999; Sorsa et al., 2011). No presente estudo, encontramos marcante proliferação de fibras colágenas na região periapical dos grupos onde foi utilizada a EGCG, que também apresentavam-se mais maduras e com forte fluorescência verde quando comparadas ao grupo tratado com pasta à base de hidróxido de cálcio, onde as fibras estavam menos maduras e menor fluorescência verde. Sabe-se que as MMPs 2 e 9 desempenham um papel importante na resposta imune e inflamatória do hospedeiro durante a progressão da lesão periapical, promovendo a degradação da matriz extracelular, degradação do tecido pulpar e inflamação periapical (Corotti et al., 2009; Carneiro et al., 2009; Sorsa et al., 2011; Li et al., 2012; Wan et al. 2014; Carneiro et al., 2017). A MMP 2, também chamada de gelatinase A, é importante para o turnover da ECM, clivando os colágenos tipos IV, V, VII, e XI, enquanto a MMP 9 (gelatinase B) é essencial para iniciar o processo de reabsorção óssea (Chang et al., 2002), removendo a camada de colágeno da superfície óssea que é composta principalmente pelo colágeno fibrilar tipo I mineralizado (Guise, 2009) para que a desmineralização ocorra (Delaissé et al., 2000). Assim, os resultados do presente estudo podem ser decorrentes da ação da EGCG na inibição das MMPs da matriz, que pode atuar favorecendo o processo de reparação por fibroblastos. No entanto, estudos futuros devem ser realizados para avaliar possíveis efeitos adicionais da utilização de EGCG como curativo de demora na terapia endodôntica, como sua atuação na inibição das MMPs presentes na lesão periapical e também nas paredes internas do canal radicular, que poderiam ainda favorecer a reparação e adesão do material obturador nas paredes dos canais radiculares.

Assim, embora o uso de EGCG no tratamento da lesão periapical seja promissor e viável, estudos futuros devem ser realizados para avaliação de possíveis vantagens sobre as pastas à base de hidróxido de cálcio, atualmente preconizadas, 
como possível estímulo à proliferação de fibras colágenas e consequente reparação tecidual, causada pela ação da mesma na inibição de MMPs ou melhora na adesão dos cimentos obturadores às paredes do canal radicular. 



\section{Conclusão}



Com base nos resultados do presente estudo in vivo, pôde-se concluir que a utilização de formulação à base de EGCG durante tratamento endodôntico, proporcionou o processo de reparação das lesões periapicais, apresentando resultados promissores para sua possível utilização como medicação intracanal. 

REFEREANCIAS 

1. Adl A, Motamedifar M, Shams MS, Mirzaie A. Clinical investigation of the effect of calcium hydroxide intracanal dressing on bacterial lipopolysaccharide reduction from infected root canals. Australian Endodontic Journal. 2015;41(1):12-16.

2. Allaker, R.P. and Douglas, C.W. Novel anti-microbial therapies for dental plaque-related diseases. Int J Antimicrob Agents 2009; 33(1), 8-13.

3. Anghileri $\mathrm{U}$, Thouvenot P. Natural polyphenols-iron interaction: its biological importance. Biol Trace Elem Res. 2000;73(3):251-8.

4. Archilla JR, Moreira MS, Miyagi SP, Bombana AC, Gutknecht N, Marques MM. Single session of $\mathrm{Nd}$ :YAG laser intracanal irradiation neutralizes endotoxin in dental root dentin. J Biomed Opt 2012; 17(11): 118002.

5. Asahi Y, Noiri Y, Miura J, Maezono H, Yamaguchi M, Yamamoto R, Azakami H, Hayashi M, Ebisu S. Effects of the tea catechin Epigallocatechin Gallate on Porphyromonas gingivalis biofilms. J Apple Microbiol 2014;16(5):1164-71.

6. Aslan C, Melikoglu C, Ocal I, Saglam G, Sutcu R, Hosnuter M. Effect of epigallocatechin gallate on ischemia-reperfusion injury: an experimental study in a rat epigastric island flap. Int J Clin Exp Med. 2014; 15:7(1):57-66.

7. Assed $S$, Leonardo MR, Silva LAB, Ito IY. Prevalência de micro-organismos em canais radiculares de dentes com necrose pulpar e reação periapical crônica Imunofluorescência indireta- efeito do preparo biomecânico e do curativo de demora pela cultura. Rev Bras Odontol 1996;53: 24-8.

8. Assed S. Prevalência de micro-organismos em canais radiculares de dentes humanos com reação periapical crônica. Efeito do preparo biomecânico e do curativo de demora. Imunofluorescência indireta e cultura [tese]. Ribeirão Preto: Univ. de São Paulo; 1994.

9. Barbosa-Ribeiro M, De-Jesus-Soares A, Zaia AA, Ferraz CC, Almeida JF, Gomes BP. Quantification of lipoteichoic acid contents and cultivable bacteria at the different phases of the endodontic retreatment. Journal of Endodontics. 2016;42(4):552-556.

10. Basu A, Lucas E. Mechanisms and effects of green tea on cardiovascular health. Nutr Rev. 2007;65(8):361-5.

11. Borsatto MC, Correa-Afonso AM, Lucisano MP, Bezerra da Silva RA, Paula-Silva FW, Nelson-Filho P, Bezerra da Silva LA. One-session root canal treatment with antimicrobial photodynamic therapy (aPDT): an in vivo study. Int Endod J. 2016;49(6):511-8.

12. Butt MS, Ahmad RS, Sultan MT, Qayyum MM, Naz A. Green tea and anticancer perspectives: updates from last decade. Crit Rev Food Sci Nutr. 2015;55(6):792-805.

13. Byström A, Sundqvist G. The antibacterial action of sodium hypochlorite and EDTA in 60 cases of endodontic therapy. Int Endod J 1985;18(1):35-40. 
14. Capik I, Sevcikova Z, Ledecky V. Radiological and histological assessment of periapical repair after obturation of infected root canals in dogs. Acta Veterinaria Brno. $2005 ; 74(2): 237-242$.

15. Cardoso FG, Chung A, Martinho FC, Camargo CH, Carvalho CA, Gomes BP, et al. Investigation of bacterial contents from persistent endodontic infection and evaluation of their inflammatory potential. Braz Dent J. 2016;27(4):412-8.

16. Carneiro E, Menezes R, Garlet GP, Garcia RB, Bramante CM, Figueira R, et al. Expression analysis of matrix metalloproteinase- 9 in epithelialized and nonepithelialized apical periodontitis lesions. Oral Surg Oral Med Oral Pathol Oral Radiol Endod. 2009: 107(1):127-32.

17. Carneiro E, Parolin AB, Wichnieski C, Rosa EA, Silva Neto UX, Westphalen VP, et al. Expression levels of the receptor activator of Nf-kB ligand and osteoprotegerin and the number of gram-negative bacteria in symptomatic asymptomatic periapical lesions. Arch Oral Biol. 2017: 73:166-171.

18. Chakrawarti L, Agrawal R, Dang S, Gupta S, Gabrani R. (2016). Therapeutic effects of EGCG: a patent review. Expert Opinion on Therapeutic patentes. 2016;26(8):907-916.

19. Chang JZC, Hsieh YP, Lin WH, Chen HM, Kuo MYP. Activation of transforming growth factor- $\beta 1$ by thrombin via integrins av $\beta 1$, av $\beta 3$, and av $\beta 5$ in buccal fibroblasts: Suppression by epigallocatechin-3-gallate. Head \& Neck. 2017;39(7):1436-1445.

20. Chang YC, Yang SF, Lai CC, Liu JY, Hsieh YS. Regulation of matrix metalloproteinase production by citokines, pharmacological agents and periodontal pathogens in human periodontal ligament fibroblast cultures. J Periodontol Res. 2002: 37(3):196-203.

21. Chaudhry S, Yadav S, Talwar S, Verma M. Effect of EndoActivator and Er, Cr: YSGG laser activation of Qmix, as final endodontic irrigant, on sealer penetration: A Confocal microscopic study. Journal of Clinical and Experimental Dentistry. 2017;9(2): e218.

22. Chen $H$, Huang B. Pilot study of the effect of green tea extractive epigallocatechin-3gallate on degradation of collagen in dental erosion. Hua xi kou qiang yi xue za zhi= Huaxi kouqiang yixue zazhi. West China Journal of Stomatology. 2012;30(5):549-551.

23. Chen MH, Tsai CF, Hsu YW, Lu FJ. Epigallocatechin gallate eye drops protect against ultraviolet B-induced corneal oxidative damage in mice. Mol Vis 2014; 20:153-62.

24. Cohenca N, Romualdo PC, da Silva LA, da Silva RA, de Queiroz AM, De Rossi A, NelsonFilho $P$. Tissue response to root canal irrigation systems in dogs' teeth with apical periodontitis. Clin Oral Investig. 2015;19(5):1147-56.

25. Corotti MV, Zambuzzi WF, Paiva KB, Menezes R, Pinto LC, Lara VS, Granjeiro JM. Immunolocalization of matrix metalloproteinases- 2 and- 9 during apical periodontitis development. Archives of Oral Biology. 2009: 54(8), 764-771. 
26. da Silva, RAB, Leonardo MR, da Silva LAB, de Castro LMS, Rosa AL, de Oliveira PT. Effects of the association between a calcium hydroxide paste and $0.4 \%$ chlorhexidine on the development of the osteogenic phenotype in vitro. Journal of Endodontics. 2008;34(12):1485-1489.

27. Daltoé MO, Paula-Silva FWG, Faccioli LH, Gatón-Hernández PM, De Rossi A, Silva LAB. Expression of mineralization markers during pulp response to biodentine and mineral trioxide aggregate. Journal of Endodontics. 2016;42(4): 596-603.

28. Dalton BC, Orstavik D, Phillips C, Pettiette M, Trope M. Bacterial reduction with nickeltitanium rotary instrumentation. J Endod. 1998;24(11):763-7.

29. de Queiroz AM, Arid J, Nelson-Filho P, Lucisano MP, Silva RAB, Sorgi CA, Silva LAB. (2016). Correlation Between Bacterial Endotoxin Levels in Root Canals of Primary Teeth and the Periapical Lesion Area. Journal of Dentistry for Children 2016;83(1): 9-15.

30. De Rossi A, De Rossi M, Rocha LB, da Silva LAB, Rossi MA. Morphometric analysis of experimentally induced periapical lesions: radiographic vs histopathological findings. Dentomaxillofacial Radiology. 2007;36(4): 211-217.

31. De Rossi A, Silva LA, Leonardo MR, Rocha LB, Rossi MA. Effect of rotary or manual instrumentation, with or without a calcium hydroxide/ $1 \%$ chlorhexidine intracanal dressing, on the healing of experimentally induced chronic periapical lesions. Oral Surg Oral Med Oral Pathol Oral Radiol Endod 2005;99(5):628-36.

32. Delaissé JM, Engsis MT, Everts V, del Carmen Ovejero M, Ferreras M, Lund L, et al. Proteinases in bone resorption: obvious and less obvious roles. Clin Chim Acta. 2000: 291(2):223-34.

33. Estrela C, Decurcio DA, de Alencar AHG, Sydney GB, Silva JA. Efficacy of calcium hydroxide dressing in endodontic infection treatment: a systematic review. Odonto Ciência. 2008;23(1):82-6.

34. Everts V, Delaissé JM, Korper W, Niehof A, Vaes G, Beertesen W. Degradation of collagen in the bone-resorbing compartment underlying the osteoclast involves both cysteine-proteinases and matrix metalloproteinases. J Cell Physiol. 1992: 150(2):22131.

35. Fang CY, Wu CC, Hsu HY, Chuang HY, Huang SY, Tsai CH, Chang Y, Tsao GS, Chen CL, Chen JY. EGCG inhibits proliferation, invasiveness and tumor growth by up-regulation of adhesion molecules, suppression of gelatinases activity, and induction of apoptosis in nasopharyngeal carcinoma cells. Int J Mol Sci. 2015;16(2):2530-58.

36. Ferreira DCA. Desenvolvimento e caracterização química de um sistema para liberação intracanal de Epigalocatequina-3-galato e seu efeito na cor dos dentes [Dissertação de Mestrado]. Ribeirão Preto: Universidade de São Paulo; 2013.

37. Ferreira DCA. Formulação à base de epigalocatequina-3-galato, derivada do chá verde, desenvolvida para uso endodôntico: estudo físico-químico e biológico [Tese de Doutorado]. Ribeirão Preto: Universidade de São Paulo, Ribeirão Preto; 2015. 
38. Fournier-Larente J, Morin MP, Grenier D. Green tea catechins potentiate the effect of antibiotics and modulate adherence and gene expression in Porphyromonas gingivalis. Archives of oral biology. 2016;65: 35-43.

39. Fu M, Fu S, Ni S, Zou L, Liu Y, Hong T. Anti-inflammatory effect of epigallocatechin gallate in a mouse model of ovalbumin-induced allergic rhinitis. International Immunopharmacology. 2017; 49:102-108.

40. Ghasempour M, Moghadamnia AA, Abedian Z, Amir MP, Feizi F, Gharekhani S. In vitro viability of human periodontal ligament cells in green tea extract. J Conserv Dent. 2015;18(1):47-50.

41. Giada MD, Mancini-Filho J. Antioxidant capacity of the striped sunflower (Helianthus annuus L.) seed extracts evaluated by three in vitro methods. International journal of food sciences and nutrition. 2009: 60(5), 395-401.

42. Gomes-Filho JE, Watanabe S, Cintra LT, Nery MJ, Dezan-Júnior E, Queiroz IO, Lodi CS, Basso MD. Effect of MTA-based sealer on the healing of periapical lesions. J Appl Oral Sci. 2013; 21(3):235-42.

43. Guise TA. Breaking Down Bone: new insight into site-specif mechanisms of brast cancer osteolysis mediated by metalloproteinases. Genes Dev. 2009: 23 (18):2117-23.

44. Gundimeda U, McNeill TH, Fan TK, Deng R, Rayudu D, Chen Z, Cadenas E, Gopalakrishna R. Green tea catechins potentiate the neuritogenic action of brainderived neurotrophic factor: Role of $67-\mathrm{kDa}$ laminin receptor and hydrogen peroxide. Biochem Biophys Res Commun 2014; 445:218-24.

45. L, Haneji T. calcium hydroxide suppresses Porphyromonas endodontalis Lipopolysaccharide-induced bone Destruction. Journal of dental research. 2014; 93(5): 508-513.

46. Hamilton-Miller JM. Anti-cariogenic properties of tea (Camellia sinensis). J Med Microbiol. 2001;50(4):299-302. Review.

47. Hidalgo $L R$, da Silva $L A B$, Nelson-Filho $P$ et al. Comparison between one-session root canal treatment with aPDT and two-session treatment with calcium hydroxide-based antibacterial dressing, in dog's teeth with apical periodontitis Lasers Med Sci 2016;31:1481.

48. Hodgson JM, Croft KD. Tea flavonoids and cardiovascular health. Mol Aspects Med. 2010;31(6):495-502.

49. Hong SW, Baik JE, Kang SS, Kum KY, Yun CH, Han SH. Sodium Hypochlorite Inactivates Lipoteichoic Acid of Enterococcus faecalis by Deacylation. Journal of Endodontics. 2016;42(10): 1503-1508.

50. Horiba N, Maekawa Y, Ito M, Matsumoto T, Nakamura H. A pilot study of Japanese green tea as a medicament: antibacterial and bactericidal effects. J Endod. $1991 ; 17(3): 122-4$. 
51. Huffaker SK, Safavi K, Spangberg LS, Kaufman B. Influence of a passive sonic irrigation system on the elimination of bacteria from root canal systems: a clinical study. J Endod. 2010;36(8):1315-8.

52. Hwang JY, Choi SC, Park JH, Kang SW.the use of green tea extract as a storage medium for the avulsed tooth. J Endod. 2011;37(7):962-7.

53. Ikigai $H$, Nakae $T$, Hara $Y$, Shimamura $T$. Bactericidal catechins damage the lipid bilayer. Biochim Biophys Acta. 1993;1147(1):132.

54. Jayashree GV, Krupashree K, Rachitha P, Khanum F. Patulin Induced Oxidative Stress Mediated Apoptotic Damage in Mice, and its Modulation by Green Tea Leaves (GTL). Journal of Clinical and Experimental Hepatology. 2017;7(2):127-134.

55. Jenabian N, Moghadamnia AA, Karami E. (2012). The effect of Camellia Sinensis (green tea) mouthwash on plaque-induced gingivitis: a single-blinded randomized controlled clinical trial. DARU Journal of Pharmaceutical Sciences. 2012;20(1):39.

56. Jeon J, Kim JH, Lee $\mathrm{CK}$, Oh $\mathrm{CH}$, Song $\mathrm{HJ}$. The Antimicrobial Activity of Epigallocatehin3-Gallate and Green Tea Extracts against Pseudomonas aeruginosa and Escherichia coli Isolated from Skin Wounds. Ann Dermatol 2014; 26:564-9.

57. Jung IH, Lee DE, Yun JH, Cho AR, Kim CS, You YJ, Kim SJ, Choi SHAnti-inflammatory effect of (-)-epigallocatechin-3-gallate on Porphyromonas gingivalis lipopolysaccharidestimulated fibroblasts and stem cells derived from human periodontal ligament. J Periodontal Implant Sci. 2012;42(6):185-95.

58. Jung IH, Yun JH, Cho AR, Kim CS, Chung WG, Choi SH. Effect of (-)-epigallocatechin-3gallate on maintaining the periodontal ligament cell viability of avulsed teeth: a preliminarystudy. J Periodontal Implant Sci 2011; 41:10-6.

59. Kakehashi S, Stanley HR, Fitzgerald RJ. The effects of surgical exposures of dental pulps in germ-free and conventional laboratory rats. Oral Surg Oral Med Oral Pathol 1965;20: 340-9.

60. Kato MT, Leite AL, Hannas AR, Buzalaf MAR. Gels containing MMP inhibitors prevent dental erosion in situ. Journal of dental research. 2010;89(5):468-472.

61. Khurshid Z, Zafar MS, Zohaib S, Najeeb S, Naseem M. Green Tea (Camellia Sinensis): Chemistry and Oral Health. The Open Dentistry Journal. 2016; 10:166-173.

62. Kim D, Kim E. Antimicrobial effect of calcium hydroxide as an intracanal medicament in root canal treatment: a literature review - Part II. In vivo studies. Restorative Dentistry \& Endodontics. 2015;40(2):97-103.

63. Kudva P, Tabasum ST, Shekhawat NK. Effect of green tea catechin, a local drug delivery system as an adjunct to scaling and root planing in chronic periodontitis patients: A clinicomicrobiological study. J Indian Soc Periodontol. 2011;15(1):39-45. 
64. Kupai K, Szucs G, Cseh S, Hajdu I, Csonka C, Csont T, Ferdinandy P. Matrix metalloproteinase activity assays: Importance of zymography. Journal of Pharmacological and toxicological methods. 2010: 61(2):205-9.

65. Kwon YS, Kim HJ, Hwang YC, Rosa V, Yu MK, Min KS. Effects of Epigallocatechin Gallate, an Antibacterial Cross-linking Agent, on Proliferation and Differentiation of Human Dental Pulp Cells Cultured in Collagen Scaffolds. Journal of endodontics. 2017;43(2):289-296.

66. Lagha $A B$, Haas $B$, Grenier $D$. Tea polyphenols inhibit the growth and virulence properties of Fusobacterium nucleatum. Scientific Reports. 2017;7: 44815.

67. Lee $\mathrm{P}$, Tan KS. Effects of Epigallocatechin gallate against Enterococcus faecalis biofilm and virulence. Arch Oral Biol. 2015 Mar;60(3):393-9.

68. Lee S, Al Razqan GS, Kwon DH. Antibacterial activity of epigallocatechin-3gallate (EGCG) and its synergism with $\beta$-lactam antibiotics sensitizing carbapenem-associated multidrug resistant clinical isolates of Acinetobacter baumannii. Phytomedicine. 2017;24: 49-55.

69. Lee $Y L$, Hong CY, Kok SH, Hou KL, Lin YT, Chen MH, Wang CC, Lin SK. An extract of green tea, epigallocatechin-3-gallate, reduces periapical lesions by inhibiting cysteinerich 61 expression in osteoblasts. J Endod. 2009;35(2):206-11.

70. Leonardo MR, da Silva LA, Leonardo RT, Utrilla LS, Assed S. Histological evaluation of therapy using a calcium hydroxide dressing for teeth with incompletely formed apices and periapical lesions. J Endod. 1993; 19(7):348-52.

71. Leonardo MR, Almeida WA, Ito IY, da Silva LAB. Radiographic and microbiologic evaluation of posttreatment apical and periapical repair of root canals of dog's teeth with experimentally induced chronic lesion. Oral Surg Oral Med Oral Pathol. $1994 ; 78(2): 232-238$.

72. Leonardo MR, Almeida WA, Silva LAB, Utrilla LS. Histopathological observations of periapical repair in teeth with radiolucent areas submitted to 2 different methods of root-canal treatment. J Endod. 1995;21(3):137-41.

73. Leornado M. Preparo biomecânico dos canais radiculares In: Endodontia: tratamento de canais radiculares: princípios técnicos e biológicos. São Paulo: Artes Médicas, I. 2005;13:450-87.

74. Leonardo MR, Hernandez ME, Silva LA, Tanomaru-Filho M. Effect of a calcium hydroxide-based root canal dressing on periapical repair in dogs: a histological study. Oral Surgery, Oral Medicine, Oral Pathology, Oral Radiology, and Endodontology. 2006;102(5):680-685. 
75. Leonardo MR, Silva LAB. Medição tópica entre-sessões. In Endodontia: tratatamento de canais radiculares. Panamericana. 1998;491-534.

76. Leonardo MR, Silva LAB.; Leonardo, RT. Tratamento de canal radicular em sessão única: Crença vs. Ciência. In: Feller C.; Gorab R, editores. Atualização na clínica odontológica: cursos antagônicos. São Paulo: Artes Médicas, 2000. p.29-57.

77. Leonardo MR, Silveira FF, Silva LA, Tanomaru Filho M, Utrilla LS. Calcium hydroxide root canal dressing. Histopathological evaluation of periapical repair at different times. Braz Dent J. 2002;13(1):17-22.

78. Li G, Yue $Y$, Tian $Y$, Li JL, Wang $M$, Liang $H$, et al. Association of matrix metalloproteinase (MMP)-1, 3, 9, interleukin (IL)-2, 8 and cyclooxygenase (COX)-2 gene polymorphismis with cronic periodontitis in a Chinese population. Cytokine. 2012: 60(2):552-60.

79. Linsuwanont $P$, Wimonsutthikul K, Pothimoke U, Santiwong,B. Treatment Outcomes of Mineral Trioxide Aggregate Pulpotomy in Vital Permanent Teeth with Carious Pulp Exposure: The Retrospective Study. Journal of Eendodontics. 2017;43(2): 225-230.

80. Madarati AA, Zafar MS, Sammani AM, Mandorah AO, Bani-Younes HA. Preference and usage of intracanal medications during endodontic treatment. Saudi Medical Journal. 2017;38(7): 755-763.

81. Mehta S, Verma P, Tikku AP, Chandra A, Bains R, Banerjee G. Comparative evaluation of antimicrobial efficacy of triple antibiotic paste, calcium hydroxide, and a proton pump inhibitor against resistant root canal pathogens. European Journal of Dentistry. 2017;11(1):53.

82. Moradzadeh M, Hosseini A, Erfanian S, Rezaei H. Epigallocatechin-3-gallate promotes apoptosis in human breast cancer T47D cells through down-regulation of PI3K/AKT and Telomerase. Pharmacological Reports. 2017; 69(5): 924-928.

83. Moreno APD. Encapsulamento de epigalocatequina-3-galato (egcg) em nanopartículas para uso tópico bucal: Desenvolvimento, caracterização e determinação da Atividade antimicrobiana in vitro [Dissertação de Mestrado]. Ribeirão Preto: Universidade de São Paulo; 2015.

84. Morin M. P Bedran, TBL, Fournier-Larente J, Haas B, Azelmat J, Grenier D. Green tea extract and its major constituent epigallocatechin-3-gallate inhibit growth and halitosisrelated properties of Solobacterium moorei. BMC complementary and alternative medicine. 2015; 15(1): 48.

85. Morin MP, Grenier D. Regulation of matrix metalloproteinase secretion by green tea catechins in a three-dimensional co-culture model of macrophages and gingival fibroblasts. Archives of oral biology. 2017;75: 89-99.

86. Munin A, Edwards-Lévy F. Encapsulation of natural polyphenolic compounds; a review. Pharmaceutics 2011; 3:793-829. 
87. Nagase H, Woessner JF Jr. Matrix Metallproteinases. J Biol Chem. 1999: $30 ; 274(31): 21491-4$.

88. Nagle DG, Ferreira D, Zhou YD. Epigallocatechin-3-gallate (EGCG): chemical and biomedical perspectives. Phytochemistry. 2006;67(17):1849-55.

89. Nair PN, Sjögren U, Figdor D, Sundqvist G. Persistent periapical radiolucencies of rootfilled human teeth, failed endodontic treatments, and periapical scars. Oral Surg Oral Med Oral Pathol Oral Radiol Endod. 1999; 87(5): 617-27.

90. Nair PN, Sjögren U, Krey G, Kahnberg KE, Sundqvist G. Intraradicular bacteria and fungi in root-filled, asymptomatic human teeth with therapy-resistant periapical lesions: a long-term light and electron microscopic follow-up study. J Endod 1990; 16(12): 580 8.

91. Nakanishi T, Mukai K, Yumoto H, Hirao K, Hosokawa Y, Matsuo T. Anti-inflammatory effect of catechin on cultured human dental pulp cells affected by bacteria-derived factors. Eur J Oral Sci. 2010;118(2):145-50.

92. Nakornchai S., Banditsing P, Visetratana N. Clinical evaluation of 3Mix and Vitapex $®$ as treatment options for pulpally involved primary molars. International Journal of Paediatric Dentistry. 2010;20(3):214-221.

93. Narotzki $B$, Reznick $A Z$, Aizenbud $D$, Levy $Y$. Green tea: a promising natural product in oral health. Arch Oral Biol. 2012;57(5):429-35.

94. Nelson-Filho P, Leonardo MR, Silva LAB, Assed S. Radiographic evaluation of the effect of endotoxin (LPS) plus calcium hydroxide on apical and periapical tissues of dogs. J Endod 2002;28(10):694-6.

95. Ng KW, Cao ZJ, Chen HB, Zhao ZZ, Zhu L, Yi T. Oolong Tea: A Critical Review of Processing Methods, Chemical Composition, Health Effects and Risk. Critical Reviews in Food Science and Nutrition. 2017: 1-24.

96. Nobrega LM, Montagner F, Ribeiro AC, Mayer MA, Gomes BP. Bacterial diversity of symptomatic primary endodontic infection by clonal analysis. Braz Oral Res. 2016;30(1):103.

97. Novy P, Rondevaldova J, Kourimska L, Kokoska L.Synergistic interactions of epigallocatechin gallate and oxytetracycline against various drug resistant Staphylococcus aureus strains in vitro. Phytomedicine. 2013;20(5):432-5.

98. Ntie-Kang F, Lifongo LL, Mbaze LM, Ekwelle N, Owono Owono LC, Megnassan E, Judson PN, Sippl W, Efange SM. Cameroonian medicinal plants: a bioactivity versus ethnobotanical survey and chemotaxonomic classification. BMC Complement Altern Med. 2013;26(13):147.

99. Oliveira KMHD, Nelson-Filho $P$, da Silva LAB, Küchler EC, Gatón-Hernandez $P$, da Silva RAB. Three-Dimensional Micro-Computed Tomography Analyses of Induced Periapical Lesions in Transgenic Mice. Ultrastructural pathology. 2016;39(6):402-407. 
100. Paikkatt JV, Aslam S, Sreedharan S, Philomina B, Kannan VP, Madhu S. Efficacy of various intracanal medicaments against aerobic and facultative anaerobic microorganism found in human primary teeth with necrotic pulp: A randomized clinical trial. Journal of Indian Society of Pedodontics and Preventive Dentistry. 2018: 36(3), 268.

101. Paikkatt JV, Sreedharan S, Philomina B, Kannan VP, Santhakumar M, Kumar TA. Efficacy of Various Intracanal Medicaments in Human Primary Teeth with Necrotic Pulp against Candida Biofilms: An in vivo Study. International journal of clinical pediatric dentistry. 2017;10(1): 45.

102. Pastoriza S, Mesías M, Cabrera C, Rufian-Henares JA. Healthy properties of Green and White teas: an update. Food \& Function. 2017; 1-11.

103. Pereira RS, Rodrigues VAA, Furtado WT, Gueiros S, Pereira GS, Avila-Campos MJ. Microbial analysis of root canal and periradicular lesion associated to teeth with endodontic failure. Anaerobe. 2017;48:12-8.

104. Pheenithicharoenkul S, Panichuttra A. Epigallocatechin-3-gallate increased the push out bond strength of an epoxy resin sealer to root dentin. Dental materials jornal. 2016; 35(6): 888-892.

105. Pirani C, Friedman S, Gatto MR, Iacono F, Tinarelli V, Gandolfi MG, et al. Survival and periapical health after root canal treatment with carrier-based root fillings: five-year retrospective assessment. Int Endod J. 2018;51:178-88.

106. Prabhakar J, Senthilkumar M, Priya MS, Mahalakshmi K, Sehgal PK, Sukumaran VG. Evaluation of antimicrobial efficacy of herbal alternatives (Triphala and green tea polyphenols), MTAD, and 5\% sodium hypochlorite against Enterococcus faecalis biofilm formed on tooth substrate: an in vitro study. J Endod. 2010;36(1):83-6.

107. Queiroz AMD, Assed S, Consolaro A, Nelson-Filho P, Leonardo MR, Silva RAB, Silva LAB. Subcutaneous connective tissue response to primary root canal filling materials. Brazilian dental jornal. 2001;22(3):203-211.

108. Reto M, Figueira ME, Filipe HM, Almeida CM. Chemical composition of green tea (Camellia sinensis) infusions commercialized in Portugal. Plant foods for human nutrition. 2007: 62(4), 139.

109. Reygaert W, Jusufi I. Green tea as an effective antimicrobial for urinary tract infections caused by Escherichia coli. Frontiers in microbiology. 2013: 4, 162.

110. Reygaert WC. The antimicrobial possibilities of green tea. Frontiers in microbiology, 2014; 5.

111. Ribeiro FC. Distribuição das bactérias nas estruturas mineralizadas dos dentes com necroes pulpar e granuloma apical [Dissertação]. Bauru: FOB- Univ de São Paulo; 1997. 
112. Ricucci D, Loghin S, Goncalves LS, Rocas IN, Siqueira JF, Jr. Histobacteriologic conditions of the apical root canal system and periapical tissues in teeth associated with sinus tracts. J Endod. 2018;44(3):405-13.

113. Riegsecker S, Wiczynski D, Kaplan MJ, Ahmed S. Potential benefits of green tea polyphenol EGCG in the prevention and treatment of vascular inflammation in rheumatoid arthritis. Life Sci 2013; 93:307-12.

114. Saito K, Mori S, Date F, Ono M. Epigallocatechin gallate inhibits oxidative stressinduced DNA damage and apoptosis in MRL-Faslpr mice with autoimmune sialadenitis via upregulation of heme oxygenase-1 and Bcl-2. Autoimmunity. 2014;47(1):13-22.

115. Scalia S, Marchetti N, Bianchi A. Comparative evaluation of different co-antioxidants on the photochemical- and functional-stability of epigallocatechin-3-gallate in topical creams exposed to simulated sunlight. Molecules 2013; 18:574-87.

116. Schäfer E, Schlingemann R. Efficiency of rotary nickel-titanium K3 instruments compared with stainless steel hand K-Flexofile. Part 2. Cleaning effectiveness and shaping ability in severely curved root canals of extracted teeth. International. Endodontic Journal. 2003;36(3):208-217.

117. Schmitz W; Saito AY; Estevão D; Saridakis HO. O chá verde e suas ações como Quimioprotetor. Semina: Ciências Biológicas e da Saúde.2005;26(2):119-130.

118. Shin YS, Seo JY, Oh SH, Kim JH, Kim ST, Park YB, Moon HS. The effects of Erh BMP-2/EGCG-coated BCP bone substitute on dehiscence around dental implants in dogs. Oral diseases. 2014; 20(3): 281-287.

119. Shuping GB, Ørstavik D, Sigurdsson A, Trope M. Reduction of intracanal bacteria using nickel-titanium rotary instrumentation and various medications. Journal of endodontics. 2000;26(12):751-755.

120. Silva LA, Nelson-Filho P, Leonardo MR, Rossi MA, Pansani CA. Effect of calcium hydroxide on bacterial endotoxin in vivo. J Endod. 2002;28(2):94-8.

121. Silva LAB, Novaes Jr AB, de Oliveira RR, Nelson-Filho P, Santamaria M Jr, Silva RAB. Antimicrobial photodynamic therapy for the treatment of teeth with apical periodontitis: a histopathological evaluation. J Endod. 2012;38(3):360-6.

122. Silva LA, Romualdo PC, Silva RA, Souza-Gugelmin MC, Pazelli LC, De Freitas AC, Faria G, Nelson-Filho P. Antibacterial Effect of Calcium Hydroxide With or Without Chlorhexidine as Intracanal Dressing in Primary Teeth With Apical Periodontitis. Pediatric Dentistry. 2017;39(1):28-33.

123. Silva $L A B$, Leonardo MR, de Oliveira DS, Silva RABD, Queiroz AM, Hernández PG, Nelson-Filho P. Histopathological evaluation of root canal filling materials for primary teeth. Brazilian dental jornal. 2010;21(1):38-45.

124. Silva LAB, Silva RAB, Branco LGS, Navarro VP, Nelson-Filho P. Quantitative radiographic evaluation of periapical bone resorption in dog's teeth contaminated with bacterial 
endotoxin (LPS) associated or not with calcium hydroxide. Brazilian dental jornal. 2008; 19(4): 296-300.

125. Sinha A, Nosoudi N, Vyavahare N. Elasto-regenerative properties of polyphenols. Biochemical and biophysical research communications. 2014;444(2):205-211.

126. Siqueira JF Jr, Alves FR, Rôças IN. Pyrosequencing analysis of the apical root canal microbiota. J Endod 2011; 37(11): 1499-503.

127. Siqueira JF Jr, Guimarães-Pinto T, Rôças IN. Effects of chemomechanical preparation with $2.5 \%$ sodium hypochlorite and intracanal medication with calcium hydroxide on cultivable bacteria in infected root canals. J Endod. 2007;33(7):800-5.

128. Siqueira JF Jr, Lima KC, Magalhães FA, Lopes HP, de Uzeda M. Mechanical reduction of the bacterial population in the root canal by three instrumentation techniques. J Endod. 1999;25(5):332-5.

129. Siqueira JF Jr, Rôças IN, Santos SR, Lima KC, Magalhães FA, de Uzeda M. Efficacy of instrumentation techniques and irrigation regimens in reducing the bacterial population within root canals. J Endod. 2002;28(3):181-4.

130. Siqueira JF, Jr., Antunes HS, Rocas IN, Rachid CT, Alves FR. Microbiome in the apical root canal system of teeth with post-treatment apical periodontitis. PLoS One. 2016;11(9):162887.

131. Sjögren U, Figdor D, Persson S, Sundqvist G. Influence of infection at the time of root filling on the outcome of endodontic treatment of teeth with apical periodontitis. Int Endod J. 1997;30(5):297-306.

132. Sjögren U, Figdor D, Spângberg L, Sundqvist G. The antimicrobial effect of calcium hydroxide as a short-term intracanal dressing. 1991;24:119-25.

133. Snoek-van B, Von Den Hoff, JW. Zymographic techniques for the analysis of matrix metalloproteinases and their inhibitors. Biotechniques. 2005: 38(1), 73-83.

134. Soares IJ, Goldberg F. Obturação do canal radicular. Endodontia: técnica e fundamentos.2001 Porto Alegre: Artmed.

135. Sorsa T, Mantyla P, Tervahartiala T, Pussinen PJ Gamonal J, Hernandez M. MMP activation in diagnostics of periodontitis and systemic inflammation. J Clin Periodontol. 2011: 38(9):817-9.

136. Stuart CH, Schwartz SA, Beeson TJ, Owatz CB. Enterococcus faecalis: its role in root canal treatment failure and current concepts in retreatment. J Endod 2006; 32:93-8.

137. Suzuki $Y$, Isemura M. Binding interaction between epigallocatechin gallate causes impaired spreading of cancer cells on fibrinogen. Biomedical Research. 2013;34(6):301-308.

138. Takagaki A, Nanjo F. Effects of metabolites produced from (-)-epigallocatechin gallate by rat intestinal bacteria on angiotensin I-converting enzyme activity and blood pressure in spontaneously hypertensive rats. Journal of agricultural and food chemistry. 2015;63(37): 8262-8266. 
139. Tan BT, Messer HH. The quality of apical canal preparation using hand and rotary instruments with specific criteria for enlargement based on initial apical file size. J Endod. 2002;28(9):658-64.

140. Tani-Ishi I. Changes in root canal microbiota during development of root periapical lesions. Oral Microbiol Imunol 1994; 9: 129-35.

141. Tanomaru JMG, Leonardo MR, Tanomaru Filho M, Bonetti Filho I, Silva LAB. Effect of different irrigation solutions and calcium hydroxide on bacterial LPS. International endodontic jornal. 2003;36(11):733-739.

142. Tanomaru JMG, Leonardo MR, Tanomaru-Filho M, Silva LAB, Ito IY. Microbial distribution in the root canal system after periapical lesion induction using different methods. Brazilian dental jornal. 2008;19(2): 124-129.

143. Tarahovsky YS, Kim YA, Yagolnik EA, Muzafarov EN. Flavonoid-membrane interactions: Involvement of flavonoid-metal complexes in raft signaling. Biochim Biophys Acta. 2014 Jan 26.

144. Taylor PW, Hamilton-Miller JM, Stapleton PD. Antimicrobial properties of green tea catechins. Food Sci Technol Bull. sch; 2:71-81.

145. Tenore GC, Daglia M, Ciampaglia R, Novellino E. Exploring the nutraceutical potential of polyphenols from black, green and white tea infusions - an overview. Curr Pharm Biotechnol. 2015;16(3):265-71.

146. Tian J, Tu H, Shi X, Wang X, Deng H, Li B, Du Y. Antimicrobial application of nanofibrous mats self-assembled with chitosan and epigallocatechin gallate. Colloids and Surfaces B: Biointerfaces. 2016;145: 643-652.

147. Trairatvorakul C, Detsomboonrat P. Success rates of a mixture of ciprofloxacin, metronidazole, and minocycline antibiotics used in the non-instrumentation endodontic treatment of mandibular primary molars with carious pulpal involvement. International journal of paediatric dentistry. 2012;22(3):217-227.

148. Tronstad L. Recent development in endodontic research. Scand J Dent Res 1992; 100(1): 52-9.

149. Tsuji M, Yamasaki M, Amano K, Matsui H, Morimoto T, Nakamura H. Histochemical localization of neutral proteases released during development of rat periradicular lesion. Arch Oral Biol. 2009: 54(12):1128-35.

150. Türközü $D$, Tek NA. A minireview of effects of green tea on energy expenditure. Critical reviews in food science and nutrition. 2017;57(2): 254-258.

151. Uchiyama Y, Suzuki T, Mochizuki K, Goda T. Dietary Supplementation with a Low Dose of (-)-Epigallocatechin-3-Gallate Reduces Pro-Inflammatory Responses in Peripheral Leukocytes of Non-Obese Type 2 Diabetic GK Rats. J Nutr Sci Vitaminol (Tokyo). 2013;59(6):541-7. 
152. Vert $M$, Hellwich $K H$, Hess $M$, Hodge $P$, Kubisa $P$, Rinaudo $M$, Schué F. Terminology for biorelated polymers and applications (IUPAC Recommendations 2012). Pure and Applied Chemistry 2012;84(2):377-410.

153. Victorino FR, Bramante CM, Zapata RO, Casaroto AR, Garcia RB, de Moraes IG, Hidalgo MM. Removal efficiency of propolis paste dressing from the root canal. J Appl Oral Sci. 2010;18(6):621-624.

154. Vilela MM. Formulação à base de um extrato do chá verde desenvolvida para uso bucal: Avaliação da atividade antimicrobiana e da alteração de cor dental [Dissertação de Mestrado]. Ribeirão Preto: Universidade de São Paulo; 2015.

155. Walker JM, Klakotskaia D, Ajit D, Weisman GA, Wood WG, Sun GY, Serfozo P, Simonyi A, Schachtman TR. Beneficial effects of dietary EGCG and voluntary exercise on behavior in an Alzheimer's disease mouse model. J Alzheimers Dis 2015; 44:561-72.

156. Wan C, Yuan G, Yang J, Sun Q, Zhang L, Zhang J, et al. MMP9 deficiency increased the size of experimentally induced apical periodontitis. J Endod. 2014: 40(5):658-64.

157. Wang F, Chang Z, Fan Q, Wang L. Epigallocatechin-3-gallate inhibits the proliferation and migration of human ovarian carcinoma cells by modulating p38 kinase and matrix metalloproteinase-2. Mol Med Rep. 2014;9(3):1085-9.

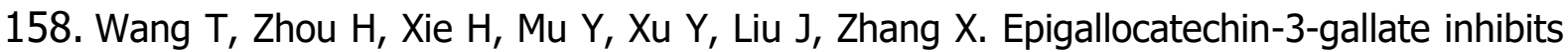
TF and TNF-a expression induced by the anti-B2GPI/B2GPI complex in human THP-1 cells. Int J Mol Med. 2014;33(4):994-1002.

159. Wen WC, Kuo PJ, Chiang CY, Chin YT, Fu MM, Fu E. Epigallocatechin-3-gallate. Attenuates Porphyromonas Gingivalis Lipopolysaccharide-enhanced Matrix Metalloproteinase-1 Production Through an Inhibition of Interleukin-6 in Gingival Fibroblasts. 2014;85(6):868-75.

160. Weng LX, Wang GH, Yao H, Yu MF, Lin J. Epigallocatechin gallate inhibits the growth of salivary adenoid cystic carcinoma cells via the EGFR/Erk signal transduction pathway and the mitochondria apoptosis pathway. Neoplasma. 2017;64.

161. Yang GY, Liao J, Kim K, Yurkow EJ, Yang CS. Inhibition of growth and induction of apoptosis in human cancer cell lines by tea polyphenols. Carcinogenesis 1998; 19:6116.

162. Yoshino S, Mitoma T, Tsuruta K, Todo H, Sugibayashi K. Effect of emulsification on the skin permeation and UV protection of catechin. Pharm Dev Technol 2014; 19:395-400.

163. Yousaf S, Butt MS, Suleria HA, Iqbal MJ. The role of green tea extract and powder in mitigating metabolic syndromes with special reference to hyperglycemia and hypercholesterolemia. 2014;5(3):545-56.

164. Yu J, Yang H, Li K, Ren H, Lei J, Huang C. Development of epigallocatechin-3-gallateencapsulated nanohydroxyapatite/mesoporous silica for therapeutic management of dentin surface. ACS applied materials \& interfaces. 2017: 9(31), 25796-25807. 
165. Zancan RF, Vivan RR, Lopes MRM, Weckwerth PH, de Andrade FB, Ponce JB, Duarte MAH. Antimicrobial Activity and Physicochemical Properties of Calcium Hydroxide Pastes Used as Intracanal Medication. Journal of endodontics. 2016;42(12): 18221828.

166. Zhao XD, Liu H, Li T, Gong Q, Zhang WL. Epigallocatechin Gallate Attenuates Hip Fracture-Induced Acute Lung Injury by Limiting Mitochondrial DNA (mtDNA) Release. Medical Science Monitor. 2017;23: 3367-3372.

167. Zhou J, Farah BL, Sinha RA, Wu Y, Singh BK, Bay BH, Yang CS, Yen PM. Epigallocatechin-3-Gallate (EGCG), a Green Tea Polyphenol, Stimulates Hepatic Autophagy and Lipid Clearance. PLoS One. 2014;29;9(1): e87161. 
Anexos 

ANEXO A- Aprovação do projeto pelo Comitê de Ética no Uso de Animais.

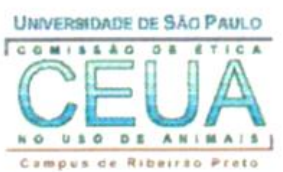

\author{
UNIVERSIDADE DE SÃO PAULO \\ Campus de Ribeirão Preto \\ Comissão de Ética no Uso de Animais
}

\title{
C E R T I F I C A D O
}

Certificamos que o trabalho (Proc. $n^{\circ}$ 11.1.1405.53.8) intitulado "Caracterização das Propriedades Físico-Químicas e Biológicas da Epigalocatequina-3galato, Derivada do Chá Verde, para uso Terapêutico na Odontologia", de autoria de Danielly Cunha Araújo Ferreira e de Andiara De Rossi, por estar de acordo com os Principios Éticos na Experimentação Animal adotados pela Comissão de Ética no Uso de Animais (CEUA) da USP de Ribeirão Preto foi aprovado em reunião da CEUA de $04 / 07 / 2012$

This is to certify that the work (Proc. $n^{\circ}$ 11.1.1405.53.8), entitled: "Caracterização das Propriedades Físico-Quimicas e Biológicas da Epigalocatequina-3galato, Derivada do Chá Verde, para uso Terapêtico na Odontologia", by Danielly Cunha Araújo Ferreira and Andiara De Rossi, is in accordance with the Ethic Principles in Animal Experimentation adopted by Ethic Commission for the Use of Animals (CEUA) of the USP of Ribeirão Preto, and was approved in the meeting, July $04,2012$.

Ribeirão Preto, 6 de julho de 2012.

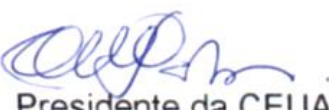

Presidente da CEUA

Profa. Dra. Cláudia Maria Padovan

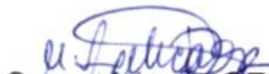

Secretaria da CEUA

Maria Angélica Depiro

Av. Bandeirantes, 3900 - CEP 14040-900 - Ribeirăo Preto - São Paulo Fone: (16) 36024469 - Fax: (16) 36337964 
ANEXO B- Especificações do fabricante da EGCG.

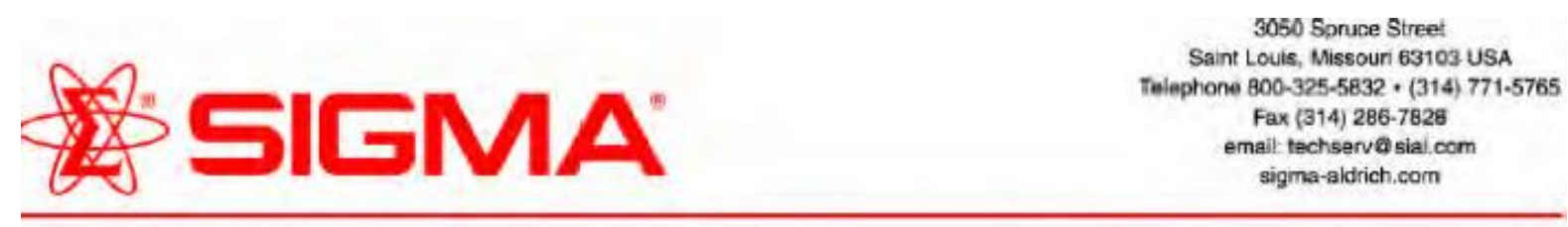

\section{Productinformation}

\section{(-)-EPIGALLOCATECHIN GALLATE}

Sigma Prod. No. E4143

Store at $2-8^{\circ} \mathrm{C}$

CAS NUMBER: $989-51-5$

SYNONYM: (2R,3R)-2-(3,4,5-Trihydrcxyphenyl)3,4-dihydro-1(2H)-benzopyran-3,5,7-triol 3-(3,4,5trihydroxybenzoate); (-)-Epigallocatechin 3-Ogallate'; $\mathrm{EGCG}^{1}$

\section{PHYSICAL DESCRIPTION:}

Appearance: powder

Molecular formula: $\mathrm{C}_{22} \mathrm{H}_{18} \mathrm{O}_{11}$

Molecular weight: 458.4

Melting point: $218^{\circ} \mathrm{C}^{\prime}$

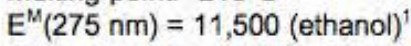

Optical rotation: $-185^{\circ} \pm 2^{\circ}$ (ethanol) ${ }^{1}$

STORAGE / STABILITY AS SUPPLIED:

\section{SOLUBILITY:}<smiles>O=C(O[C@H]1Cc2c(O)cc(O)cc2O[C@@H]1c1cc(O)c(O)c(O)c1)c1cc(O)c(O)c(O)c1</smiles>

This is soluble in water at least to $5 \mathrm{mg} / \mathrm{mL}$, giving a clear faint yellow solution. The stability of a solution of this product in water at a concentration of $0.3 \mathrm{mg} / \mathrm{mL}$ was tested. A sample left for 2.5 hours at room temperature was found to have significantly decreased in purity (from $99.6 \%$ to $81.7 \%$, by HPLC). A sample left for 2 hours at $4^{\circ} \mathrm{C}$ was found to have decreased only slightly (from $99.5 \%$ to $99.3 \%$ ).

\section{GENERAL NOTES:}

Epigallocatechin gallate (EGCG) is a polyphenolic compound found in green tea leaves. Studies with EGCG indicate it has antitumor promoting activity. ${ }^{12}$

\section{METHOD OF PREPARATION:}

It is isolated by extracting the tea leaves with hot water, back-extracted with ethyl acetate. The EGCG is chromatographically isolated from the organic phase. ${ }^{3}$ 


\section{(-)-EPIGALLOCATECHIN GALLATE}

Sigma Prod. No. E4143

\section{HPLC SYSTEM: ${ }^{4}$}

Column: YMC ODS-A $15 \mathrm{~cm} \times 4.6 \mathrm{~mm}$ ID Particle size $5 \mu \mathrm{m}$

Mobile phase:acetonitrile:ethyl acetate: $0.25 \% \mathrm{H}_{3} \mathrm{PO}_{4}(12: 2: 86)$

Flow rate: $1.0 \mathrm{~mL} / \mathrm{min}$

Solvent: Product dissolved at $0.3 \mathrm{mg} / \mathrm{mL}$ in water, $20 \mu \mathrm{L}$ injected

Detection at $280 \mathrm{~nm}$

Retention time for major peak $\approx 12$ minutes

Determination of this compound in plasme and urine by HPLC has been reported. ${ }^{5}$

\section{REFERENCES:}

1. Merck Index, 12th ed., \#3568 (1996).

2. Yamane, T. et al., Cancer Res., 55, 2081 (1995).

3. Supplier information.

4. Sigma quality control.

5. Lee, M.J. et al., Cancer Epidemiol. Biomark. Prev., 4, 393 (1995).

Sigma warrants that its products conform to the information contained in this and other SigmaAldrich publications. Purchaser must determine the suitability of the product(s) for their particular use. Additional terms and conditions may apply. Please see reverse side of the invoice or packing slip. 